\title{
Progress on pivotal role and application of exosome in lung cancer carcinogenesis, diagnosis, therapy and prognosis
}

\author{
Ming-Yue Li', Li-Zhong Liu' ${ }^{2^{*}}$ and Ming Dong ${ }^{1 *}$ (D)
}

\begin{abstract}
Lung cancer is often diagnosed at an advanced stage and has a poor prognosis. Conventional treatments are not effective for metastatic lung cancer therapy. Although some of molecular targets have been identified with favorable response, those targets cannot be exploited due to the lack of suitable drug carriers. Lung cancer cellderived exosomes (LCCDEs) receive recent interest in its role in carcinogenesis, diagnosis, therapy, and prognosis of lung cancer due to its biological functions and natural ability to carry donor cell biomolecules. LCCDEs can promote cell proliferation and metastasis, affect angiogenesis, modulate antitumor immune responses during lung cancer carcinogenesis, regulate drug resistance in lung cancer therapy, and be now considered an important component in liquid biopsy assessments for detecting lung cancer. Therapeutic deliverable exosomes are emerging as promising drug delivery agents specifically to tumor high precision medicine because of their natural intercellular communication role, excellent biocompatibility, low immunogenicity, low toxicity, long blood circulation ability, biodegradable characteristics, and their ability to cross various biological barriers. Several studies are currently underway to develop novel diagnostic and prognostic modalities using LCCDEs, and to develop methods of exploiting exosomes for use as efficient drug delivery vehicles. Current status of lung cancer and extensive applicability of LCCDEs are illustrated in this review. The promising data and technologies indicate that the approach on LCCDEs implies the potential application of LCCDEs to clinical management of lung cancer patients.
\end{abstract}

Keywords: Lung cancer cell-derived exosomes (LCCDEs), carcinogenesis, diagnosis, therapy, prognosis

\section{Background}

Lung cancer is the most frequent cancer and leading cause of cancer death worldwide [1]. Small-cell lung carcinoma (SCLC) and non-small cell lung carcinoma (NSCLC), accounting for $15 \%$ and $85 \%$ of all lung cancers respectively, are two main subtypes [2]. SCLC is highly related to smoking. NSCLC is further classified

\footnotetext{
*Correspondence: liulz@szu.edu.cn; dong_ming@grmh-gdl.cn

${ }^{2}$ Department of Physiology, School of Medicine, Shenzhen University Health

Science Center, Shenzhen University, A7-304, Shenzhen University Xili Campus, Nanshan District, Shenzhen 518055, China

${ }^{1}$ Biomedical Equipment Department, Bioland Laboratory (Guangzhou Regenerative Medicine and Health Guangdong Laboratory), Building 3, No.188, KaiYuan Road, Huangpu District, Guangzhou, Guangdong, China
}

into three main types: squamous cell carcinoma (SCC), adenocarcinoma (AD), and large cell carcinoma (LCC) [2]. SCC and LCC, comprising $25-30 \%$ and $5-10 \%$ of all lung cancer cases respectively, are strongly correlated with cigarette smoking $[3,4]$. AD is the most common type both in smokers and nonsmokers and comprises $40-45 \%$ of all lung cancer cases [5]. Tumor stage is important for treatment and prognosis. The 5-year survival of lung cancer is about 19\% [6]. Low lung cancer survival rate is due to more than $50 \%$ NSCLC patients diagnosed with metastatic disease [7]. Patients with earlystage lung cancer have better prognosis than those with more advanced stage. 5-year relative survival rate

(c) The Author(s). 2021 Open Access This article is licensed under a Creative Commons Attribution 4.0 International License, which permits use, sharing, adaptation, distribution and reproduction in any medium or format, as long as you give appropriate credit to the original author(s) and the source, provide a link to the Creative Commons licence, and indicate if changes were made. The images or other third party material in this article are included in the article's Creative Commons licence, unless indicated otherwise in a credit line to the material. If material is not included in the article's Creative Commons licence and your intended use is not permitted by statutory regulation or exceeds the permitted use, you will need to obtain permission directly from the copyright holder. To view a copy of this licence, visit http://creativecommons.org/licenses/by/4.0/ The Creative Commons Public Domain Dedication waiver (http://creativecommons.org/publicdomain/zero/1.0/) applies to the data made available in this article, unless otherwise stated in a credit line to the data. 
reaches $90 \%$ for stage $1 \mathrm{~A} 1$ but drops below $10 \%$ for stage 4 NSCLC. Among patients with SCLC, 5-year relative survival rates are about $30 \%$ for limited disease and below $10 \%$ for extensive disease [8]. Because of its extraordinary disease burden and international variability in trends of population growth, aging, and smoking behaviors, the global lung cancer epidemiology requires continual monitoring [9].

All cells release extracellular vesicles, which are broadly divided into two categories of ectosomes and exosomes, as part of their normal or abnormal physiology [10]. Exosomes are endosomal origin and nanosized vesicles with a size range of $\sim 40-160 \mathrm{~nm}$ (average $\sim 100 \mathrm{~nm}$ ) in diameter [10]. One speculated role of exosomes is to remove excess and/or unnecessary constituents from cells to maintain cellular homeostasis [10]. When exosomes are taken up by other cells, the cargoes are transferred and influence the phenotype of recipient cells, indicating exosomes as essential mediators of cellcell communication [11]. Current status of lung cancer and extensive applicability of Lung cancer cell-derived exosomes (LCCDEs) are illustrated in this review. LCCD Es participate in lung cancer carcinogenesis and drug resistance. Functional study of LCCDEs is useful to elucidate the pathogenesis of lung cancer. LCCDEs contain potential diagnostic and prognostic biomarkers, which can be developed for liquid biopsy of lung cancer. Delivery of therapeutic agents by engineering LCCDEs is a novel approach for lung cancer precision and personalized therapy.

\section{Risk factors for lung cancer}

Risk factors for developing lung cancer have been identified, with cigarette smoking being a major factor along with other environmental, chronic disease, and genetic risk factors. Since about $80 \%$ of lung cancers develop in current or former tobacco smokers and up to $20 \%$ of all cancer deaths worldwide could be prevented by tobacco smoking elimination, cigarette smoking outweighs all other factors [8]. At least 50 carcinogens has been identified in tobacco smoke, of which, tobacco-specific $\mathrm{N}$-nitrosamines formed by nicotine nitrosation are particularly concerned [12]. And tobacco-specific Nnitrosamine 4-(methylnitrosamino)-1(3-pyridyl)-1-butanone (NNK) seems to be the most important lung cancer inducer [13]. Global statistics indicates that lung cancer in never smokers (LCNS) accounts for about 20\% of lung cancer [14]. At least $17 \%$ of LCNS are attributable to exposure to high levels of environmental tobacco smoke (ETS) or secondhand smoke [15]. 24\% excess risk for lung cancer is found in nonsmokers who lives with a smoker [16].

The incidence of lung cancer without tobacco smoking history is increasing [17]. The polluted air, especially particulate matter $2.5\left(\mathrm{PM}_{2.5}\right)$ has been indicated as the major factor for LCNS incidence [18]. Air pollution has been a major environmental problem for more than two decades and is worsening in many large populated cities [19]. Air pollution, especially $\mathrm{PM}_{2.5}$ exposure, is associated with the increased lung cancer risk and mortality independent of cigarette smoking [20]. It is difficult to pinpoint the carcinogenic role played by single constituent of air pollution. Significant associations are found with specific $\mathrm{PM}$ components such as $\mathrm{PM}_{2.5}$ and lung cancer [21]. $\mathrm{PM}_{2.5}$ concentration plays a dominant role in inducing lung cancer, which is consistent with the evidence that lung cancer incidence without tobacco smoking history is increasing in some large cities with air pollution problem $[22,23]$. The increased risk estimates of lung cancer are observed for each $10 \mu \mathrm{g} / \mathrm{m}^{3}$ increment in $\mathrm{PM}_{2.5}$ concentration [24]. There is an excess risk of approximately $19 \%$ for lung cancer per $10 \mathrm{mg} / \mathrm{m}^{3}$ increment in the long-term average exposure to fine particulates [25]. A meta-analysis finds significant association between risk for lung cancer and $\mathrm{PM}_{2.5}$ (HR 1.18 per 5 $\mathrm{mg} / \mathrm{m}^{3}$ ) [26].

Chronic Diseases and metabolic disorders affect lung cancer mortality. Chronic lung Diseases, such as COPD, Alpha1-antitrypsin deficiency carriers, patients with interstitial fibrosis or idiopathic pulmonary fibrosis, have shown strong association with lung cancer [27-30]. Cancer-related lung cancer death is higher among people with diabetes [31]. Compared with normal weight, the relative risk for lung cancer is 0.77 for excess body weight with a BMI of $25 \mathrm{~kg} / \mathrm{m}^{2}$ or greater [32], while underweight is associated with lower lung cancer risk in a nonlinear, inverted U-shaped relationship [33]. Waist circumference has been found to be positively associated with lung cancer risk in smokers [34].

Genetic components, relating to host susceptibility to cigarette smoke exposure and to certain types of lung cancer development or to an individual responsiveness to therapies, are risk factors of lung cancer pathogenesis. The importance of lung cancer family history with early onset of lung cancer family members, has been highlighted by the incorporation into several lung cancer risk prediction algorithms [35, 36]. The findings on familial aggregation of lung cancer are consistent with a two-fold increase risk for lung cancer in smokers with a family history of lung cancer and also with an increased risk present in non-smokers [37]. Large-effect genomewide associations for SCC with the rare variants BRCA2 and CHEK2 has been described [38]. The direct evidence is also provided by the increased risk of lung cancer associated with rare Mendelian cancer syndromes in carriers of constitutional TP53, retinoblastoma gene mutations, xeroderma pigmentosum, Bloom's and Werner's syndromes [39-43]. 
Currently, most patients with lung cancer are diagnosed in the advanced stage, which makes the cancer difficult to surgically resect and increases the postoperative recurrence rate. On the other hand, lung cancer treatment is evolving to precision therapy based on changes in molecular and gene levels [44]. The relative information of lung cancer is summarized in Fig. 1. Further investigation on lung cancer carcinogenesis, diagnosis, therapy, and prognosis will significantly improve the overall survival of patients with lung cancer.

\section{Exosome and its biological properties and functions}

Exosomes are endosomal origin and nano-sized vesicles with a size range of $\sim 40-160 \mathrm{~nm}$ (average $\sim 100 \mathrm{~nm}$ ) in diameter [10]. All cells release extracellular vesicles (EVs), which are broadly divided into ectosomes and exosomes. Ectosomes (size range of $\sim 50 \mathrm{~nm}-1 \mathrm{~mm}$ in diameter) pinch off the surface of the plasma membrane via outward budding. Exosomes are endosomal origin and nano-sized vesicles with a size range of $\sim 40-160 \mathrm{~nm}$ (average $\sim 100 \mathrm{~nm}$ ) in diameter. Hence, two defining distinctions between ectosomes and exosomes include the site of biogenesis and particle size. More and more studies have focused on exosomes because of their crucial roles in cellular homeostasis maintenance and cell communication under pathological or physiological conditions, in exosome-based non-invasive liquid biopsy diagnosis, and in their application of drug delivery [10]. Exosomes are enclosed by a lipid bilayer and contain many cell constituents, including cytosolic and cell surface proteins, glycans, lipids, metabolites, amino acids, RNA, and DNA [11]. The structure and contents of exosomes are demonstrated in Fig. 2. So far, 9769 proteins, 3408 mRNA, 2838 miRNAs and 1116 lipids in various exosomes from different types of cells have been discerned [45].

Surrounding by a host-cell-origin lipid membrane, exosome exhibits intrinsic organotropic and displays tissue tropism mediated by surface molecules, such as integrins and glycans [46]. Exosomal tetraspanin complexes as constitutive components are also involved in the target cell selection [47]. Exosomes possess properties of excellent stability, biocompatibility, biological barrier permeability, long body circulations, low toxicity, low immunogenicity, and unique surface protein expression originated from their parental cells, all of which are good for their target delivery [48]. Because of these properties, exosomes play significant roles in various biological functions and regulate numerous physiological and pathological processes in various diseases. Also, exosomes are promising biomarkers for diagnosis/prognosis of various diseases, which may contribute to the development of minimally invasive diagnosis and next generation therapies. Exosome functions depend on their ability to interact with recipient cells and deliver their contents to these cells [49]. Exosomes are involved in obsolete molecules eradication [50]; antigen presentation [51]; tumor progression, by promoting angiogenesis and

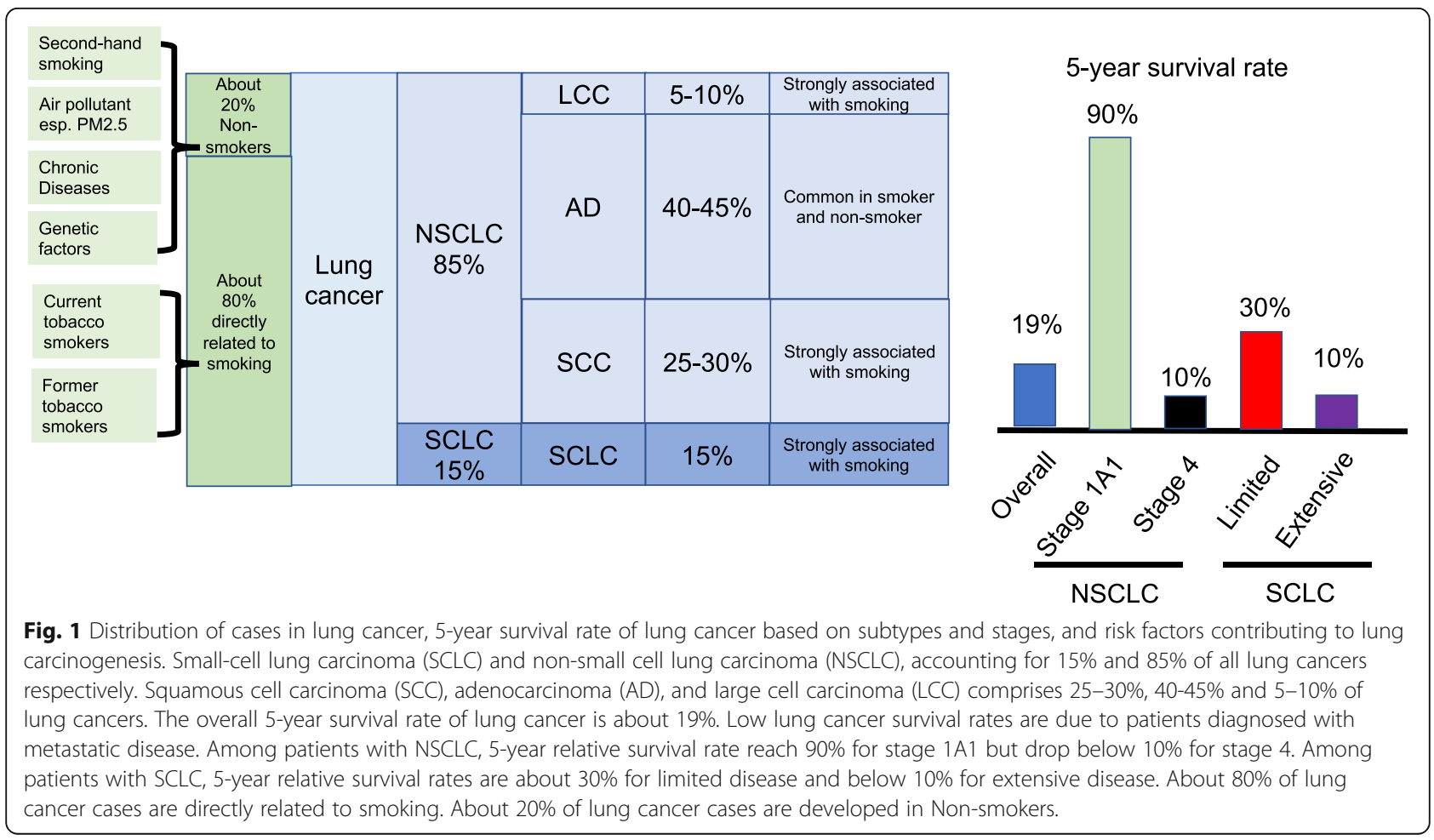




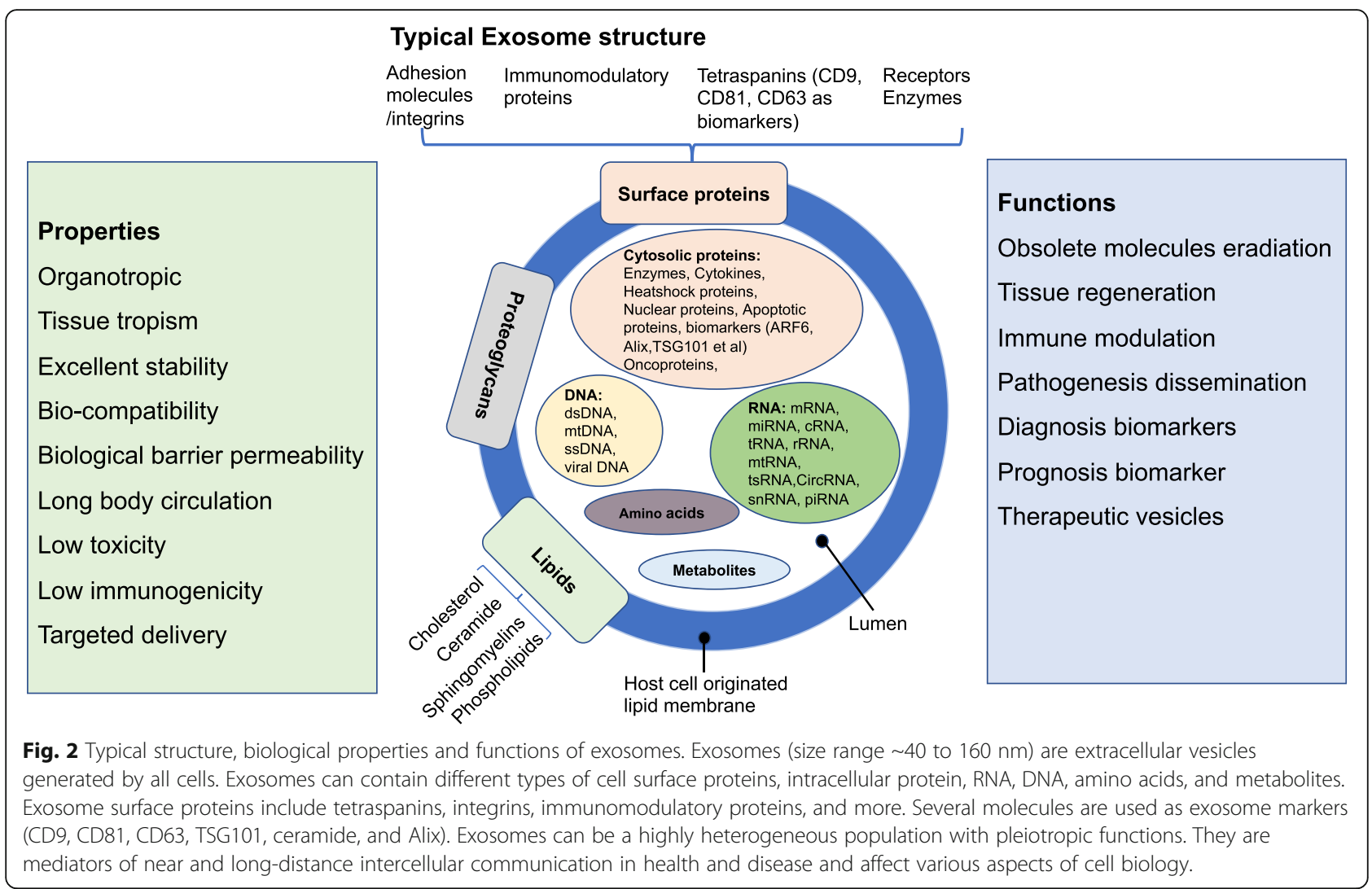

tumor cell growth and migration [11], regulatory T lymphocytes differentiation or myeloid cells suppressing immune responses [52]; and pathogenesis dissemination through interaction with recipient cells [53]. The biocompatible nature of exosomes could enhance the stability and efficacy of imaging probes and therapeutics [54]. Due to their potential use in clinical applications, exosomes have attracted much research attention on their roles in health and disease. The biological properties and functions of exosome are summarized in Fig. 2.

\section{Exosome biogenesis and cellular uptake}

Exosome biogenesis originates in the endocytic pathway $[10,11]$. It begins with invagination of endosomal limiting membranes by formation of the early sorting endosomes (ESEs). Some of ESEs therefore contain membrane and luminal constituents, which can represent diverse origins. ESEs give rise to late sorting endosomes (LSEs). Second invagination in the LSE leads to generation of intraluminal vesicles (ILVs). This step can lead to further modification of cargoes in the future exosomes, and ultimately form multivesicular bodies (MVBs). Some MVBs end up in lysosomes with enzymes to degrade the components of MVBs. However, some MVBs escape degradation due to the presence of specific surface proteins, such as tetraspanins and lysosomalassociated membrane proteins LAMP1 and LAMP2.
These MVBs then fuse with the plasma membrane and get released as vesicles termed as exosomes [55]. Exosome formation requires the coordinated efforts of several protein networks in cell: Rab GTPase proteins control endosomal trafficking [56]; endosomal sorting complexes required for transport (ESCRT), which consists of multiple protein complexes, regulate ILV formation [57]; tetraspanins as transmembrane proteins induce membrane curvatures to enable vesicle formation [58]; and various lipid-modifying enzymes (such as sphingomyelinase, which generates ceramides) promote vesicle formation [59]. TSG101 (tumor susceptibility gene 101) [60], ALIX (apoptosis-linked gene 2interacting protein $\mathrm{X}) /$ Syntenin/syndecan complex [60, 61], phospholipids [62], Flotillin [63], ARF6 and SNARE complex proteins [64] are also involved in the origin and biogenesis process of exosomes, although their functions in exosome biogenesis require further exploration. These factors interact directly with exosomal cargoes and are tightly coupled with the destined substrates for exosome secretion.

Several mechanisms and pathways have been associated with exosome uptake $[65,66]$, Exosome fusion with cellular membrane of recipient cell lead to the release of exosomal cargoes into cytoplasm. Human melanoma cells uptake exosomal cargoes through exosome fusion with the plasma membrane [67]. Juxtracrine signaling 
through receptor-ligand interactions is also involved in cellular uptake of exosome. There are several proteins that may act as potential receptors for exosome uptake, such as Tim $1 / 4$ for B cells [68] and ICAM-1 for APCs [69]. Various types of endocytosis have been identified as possible mechanisms of cellular uptake of exosome. Endocytosis by phagocytosis and micropinocytosis are much more common method of exosome uptake [70, 71]. Clathrin-dependent endocytosis [72, 73], lipid raft dependent [74], and caveolae endocytosis [64] are the other three kinds of endocytosis for exosome uptake.

In any given cell, exosome biogenesis and cellular uptake pathways may intersect, resulting in a composition of net production of mixed endogenous and exogenous exosomes population (Fig. 3).

\section{Exosome isolation and characterization}

Generally, exosomes can be isolated from a variety of body fluids and conditioned cell culture media, such as blood, semen, saliva, plasma, urine, cerebrospinal fluid, epididymal fluid, amniotic fluid, malignant and pleural effusions of ascites, bronchoalveolar lavage fluid, synovial fluid, and breast milk [75, 76]. Several conventional methods have been employed to isolate exosomes as: 1) Ultracentrifugation, including differential and densitygradient ultracentrifugation, is conventional method and suitable for pelleting lipoproteins, extravesicular protein complexes, aggregates, and other contaminants [77]. In addition, density-gradient ultracentrifugation, which separates particles by layers of biocompatible medium with varying densities (e.g., sucrose), yield the exosome preparations with a higher purity as compared to a classic ultracentrifugation and gain great popularity in the currently used exosome strategies [78]. However, it cannot apply for small volumes of clinical samples and is timeconsuming, labor-intensive, costly instrumentation requirement, and multiple overnight centrifugation steps included [77]; 2) Ultrafiltration (UF), including SizeBased Filtration, Size-Exclusion Chromatography, and Polymer Precipitation, is size-based exosome isolation method using membrane filters with defined molecular weight or size exclusion limits [79]. UF is faster than ultracentrifugation, and does not require costly equipment. The method is not suitable for exosome enrichment, and disadvantages include that different size exosomes are mixed together and non-exosome material such as protein aggregates exist [80]; 3) Immune affinity capture is applied for isolating exosomes based on specific interactions between proteins (antigens) and their antibodies or between receptors and their ligands [81]. It has been used to capture specific exosomes from a complex population, with the advantage of specificity and disadvantage of low yields; 4) Commercially available kits have been emerged to enrich exosomes, such as
ExoQuick kit (System Bioscience), Total Exosome Isolation kit (Invitrogen), qEV columns (Izon), the exoEasy Maxi kit (Qiagen), Ultrafiltration (UF) Amicon ${ }^{\circ}$ ultra-0.5 centrifugal filter devices (Millipore) [82]; 5) Microfluidics-Based Isolation Techniques are essential and important techniques for the microscale isolation, detection, and analysis of exosomes. By using both physical and biochemical properties of exosomes, this technology meets the challenge of providing high-purity exosomes for clinical settings [83]. The device with a size-based exosome isolation chip facilitates high-yield and high-purity exosome isolation from biofluids and clinical samples, including plasma, urine, and lavage, demonstrating its broad applicability to cancers and other diseases [84]. It is reported that construction of anti-CD9 antibody-coupled highly porous monolithic silica microtips allows automated, rapid and reproducible exosome extraction from multiple clinical samples [85]. A microfluidic chip for immunocapture and quantification of EpCAM-positive and HER2-positive exosomes has been developed [86]. Each approach has its advantages and disadvantages, and may be dictated by the sample source and intended exosome uses. Improvements and innovations in isolation methods are essential for translating exosome research into clinical applications and patient care.

Exosomes are characterized by size, morphology, flotation density, and presence of marker proteins $[10$, 11]. Several techniques have been routinely used to characterize exosomes. These include Dynamic light scattering (DLS) [87], Nanoparticle Tracking Analysis (NTA) [87], Tunable Resistive Pulse Sensing (TRPS) [88], Transmission Electron Microscopy (TEM) [89], Atomic Force Microscopy (AFM) [90], flow cytometry [91], and Western blot for detecting marker proteins $[10,11]$. Each of these techniques has its own limitations that must be taken into consideration: 1) DLS is an alternative technique for measuring exosome size to provide diameter range of the analyzed vesicles, while does not provide any biochemical data [87]; 2) NTA can measure the exosome movement by tracking each particle through image analysis and then to correlate this movement to particle size [87]. Advantage of using NTA includes quick sample preparation, easy and quick measurement, and samples recovery to their native form after NTA measurements. Moreover, the presence of antigens on exosomes can be detected by applying fluorescentlabeled antibodies [87, 92]; 3) TRPS, with the salient feature of in situ single-particle characterization and concentration measurement, is the most useful for measuring exosomes size distribution and concentration, characterizing particles ranging from approximately 50 $\mathrm{nm}$ in diameter up to the size of cells, and investigating cellular function and uptake [88]. Essentially, TRPS 


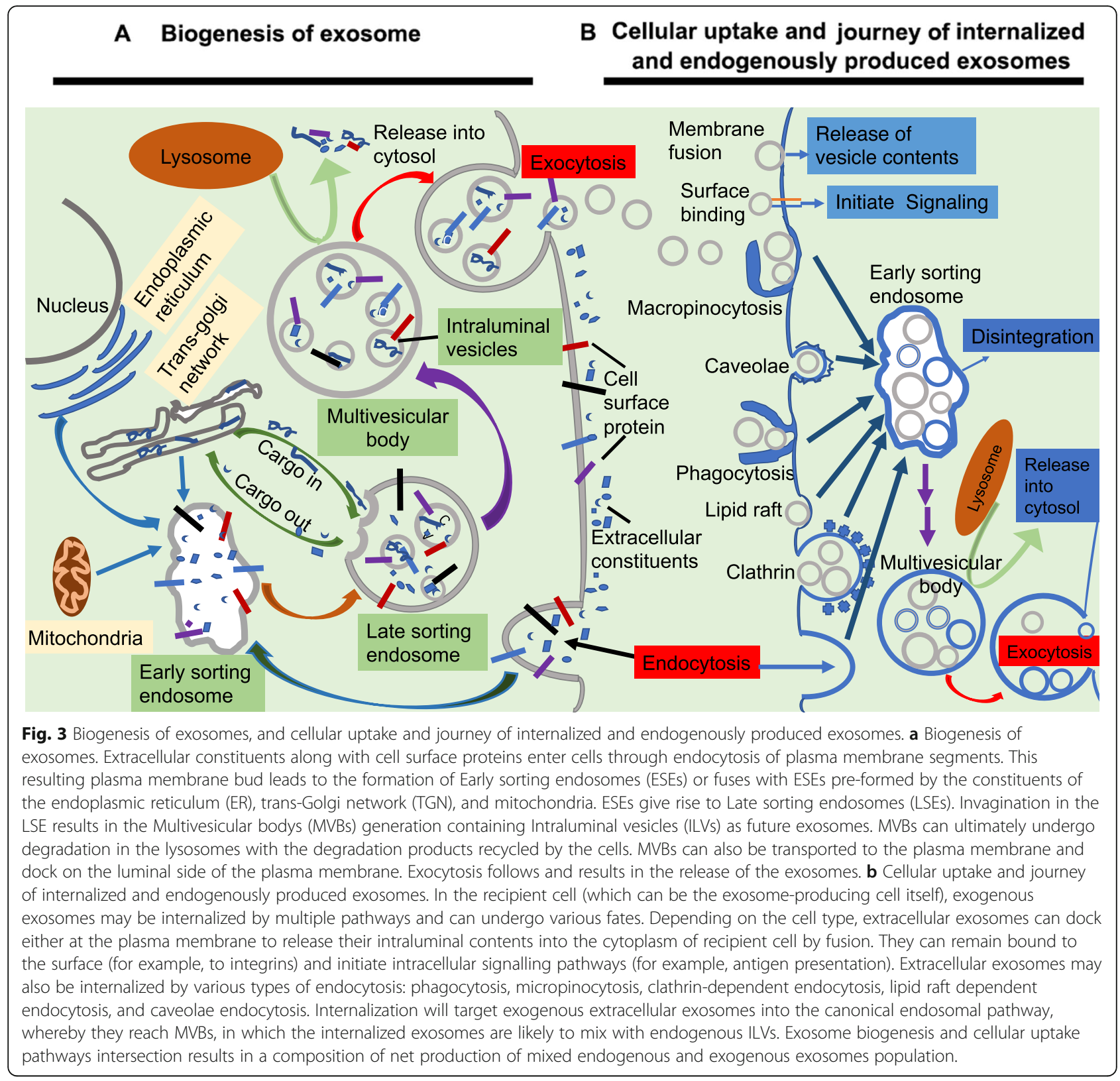

measures the brief increase in electrical resistance produced by individual nanoscale particles as they translocate through a size-tunable micrometer-sized pore. The length of the resistive pulse can be correlated to the particle size. In addition, the number of resistive pulses over a given time reveals particle concentration within a sample [88]. Its defects include system stability issues due to the blockage by particles, and sensitivity issues due to too small particles to be detected against the system background noise [88]; 4) TEM is a widely used technique to characterize the structure, morphology, and size of various biological components [89]. Consideration should be given on sample preparation, which is extensive, involves multiple steps, and may induce changes in exosome morphology. Moreover, in some cases, the electron beam may also damage biological samples. Frozen exosomes examined by cryo-TEM is an alternative method which has been shown to well maintain exosome morphology [49]; 5) AFM is a unique technique for studying exosomes, which measures samples in native conditions with minimal sample preparation and without any destructive operation mode [90]. The defect is that sample characterization carried out from external analyses lead to different experimental conditions affecting the measure [90]; 6) Flow cytometry is a molecular approach and one of the most frequently used techniques to characterize exosome size, structure, and surface proteins [91]. It is well-adapted to the reproducible 
analysis of clinical samples, allowing measurement of exosomes size and structure [91]. 7) Western blot for detecting marker proteins is also used for exosome confirmation (Fig. 1 and Fig. 4) [10, 11]. It is the most commonly used methods to quantify proteins in exosomes. Common proteins that can identify exosomes must be analyzed to demonstrate the nature, purity degree and functional activities of exosome preparation. Furthermore, several proteins that are frequently enriched in specific cancer (eg., lung) cell-derived exosomes should be considered for screening cancer biomarkers [93, 94]. The various methods of exosome isolation and routinely used techniques of exosome characterization have been summarized in Fig. 4.

\section{Tumor-derived exosomes}

Secreted by cancer cells, Tumor-derived exosomes (TDEs) might modulate the recipient cells activity and play important roles in tumor growth and metastasis through participating in cellular communications, modulating cell signaling, and contributing to pre-metastatic niche (PMN) formation [11, 95-97]. Recent evidences indicate that TDEs have significant effect on of cancer angiogenesis by transferring proteins such as VEGF, FGF, IL-6, IL-8 and angiopoietin [98]. TDEs modulate antitumor immune responses by inhibiting $\mathrm{T}$-cell activation and proliferation, inducing regulatory $\mathrm{T}$-cells and myeloid-derived suppressor cells (MDSCs), and inhibiting natural killer (NK) and CD8+ T-cells function, thus to facilitate tumor progression by evasion of host immune system [99-101]. Furthermore, TDEs from drug-resistant cancer cells incorporate cell surface P-glycoprotein from their donor cells. They effectively bind to drug-sensitive recipient cells and transfer functional P-glycoprotein to the latter, which are crucial importance in induction of signal pathway for drug resistance in recipient cells [102]. With a significantly increased number traced in cancer patient blood than in normal human blood, TDEs can be useful diagnostic and prognostic biomarkers [103]. Collectively, TDEs can promote cancer carcinogenesis, angiogenesis, and drug resistance, help cancer cell escape from host immune system, and can be useful diagnostic and/or prognostic biomarkers (Fig. 4).

\section{Exosome in lung cancer}

The poor survival rates of lung cancer are mainly due to late-stage diagnosis and/or inefficient therapeutic regimens. Lung cancer cell derived-exosomes (LCCDEs) have received recent interest in their pivotal role in lung cancer carcinogenesis, early detection/diagnosis, drug resistance, exosome drug delivery system establishment for target therapy, and prognosis, which are summarized in Table 1 and Fig. 5.
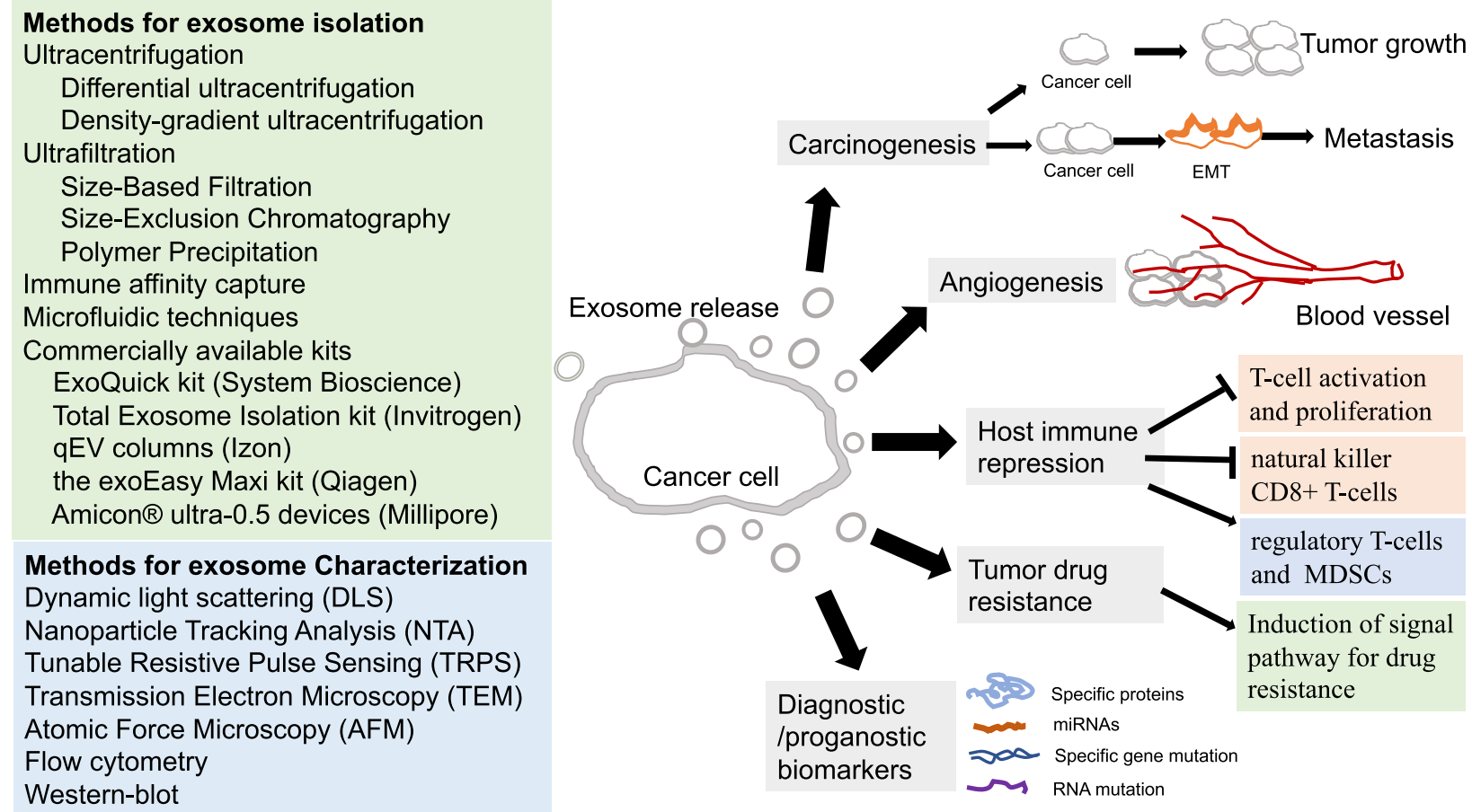

Fig. 4 Exosome isolation, characterization, and tumor-derived exosomes role in tumor development. Methods for exosome isolation and characterization are listed. Tumor-derived exosomes role in tumor development includes to promote cancer carcinogenesis, angiogenesis, and drug resistance, help cancer cell escape from host immune system, and can be useful diagnostic and/or prognostic biomarkers. 


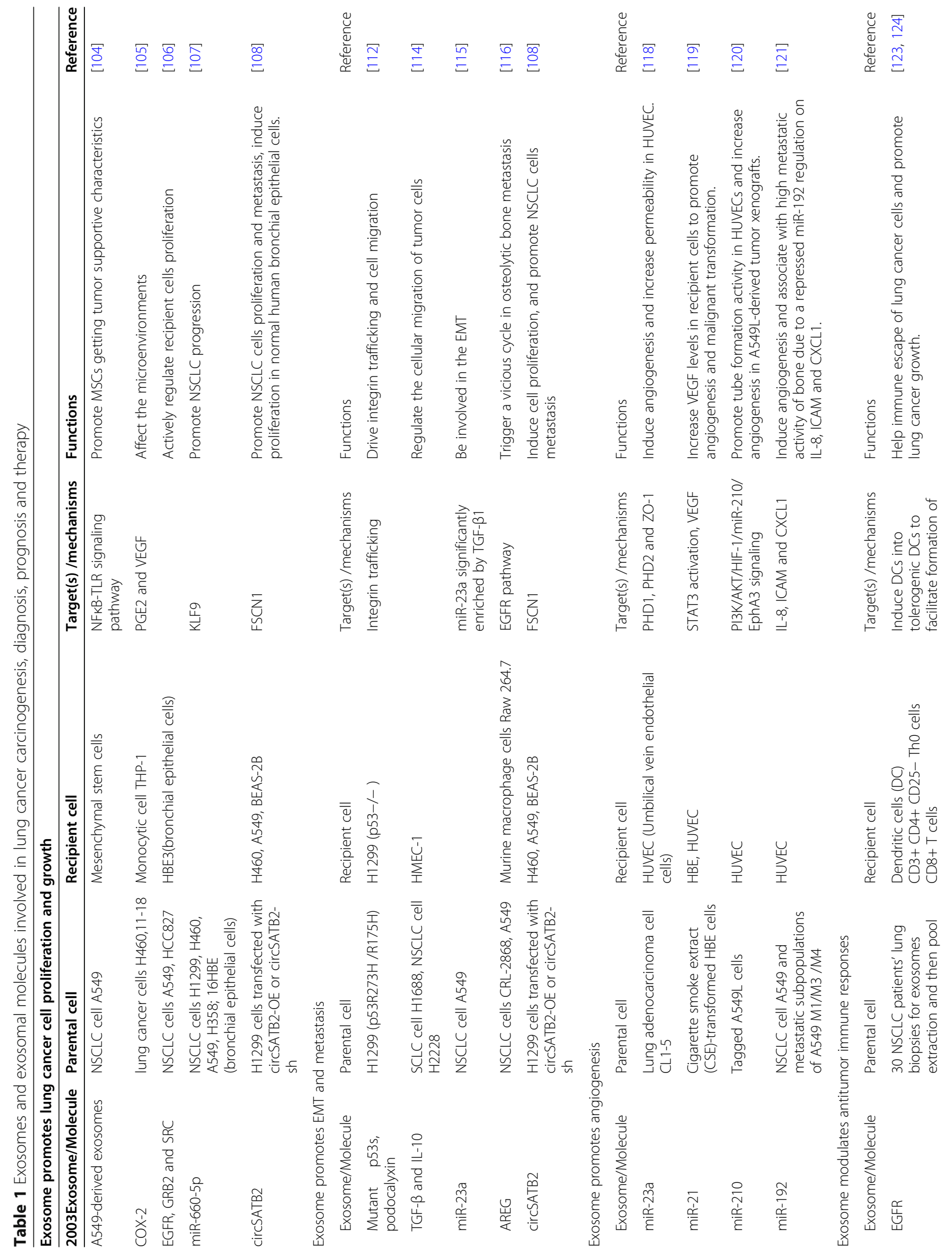




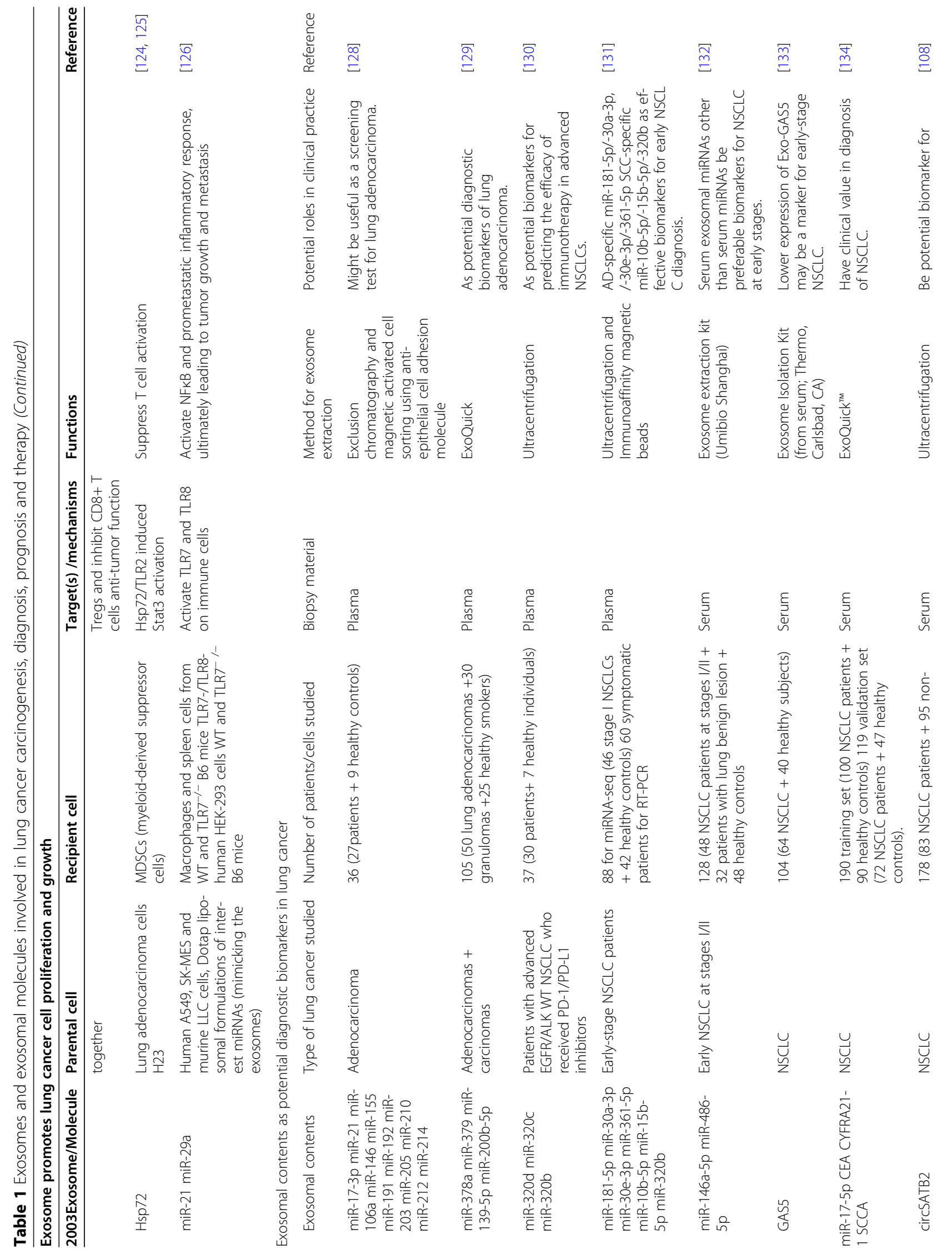




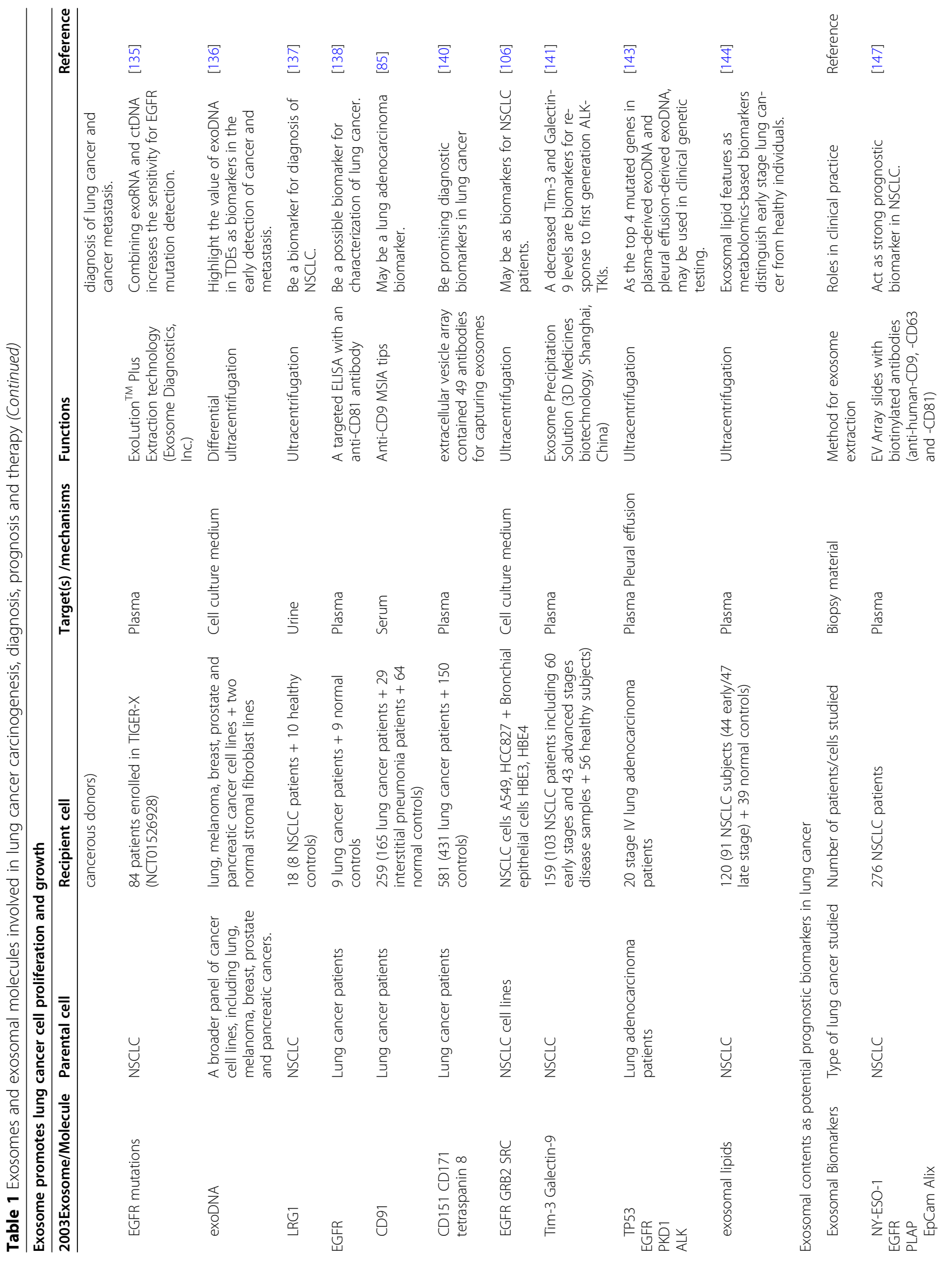




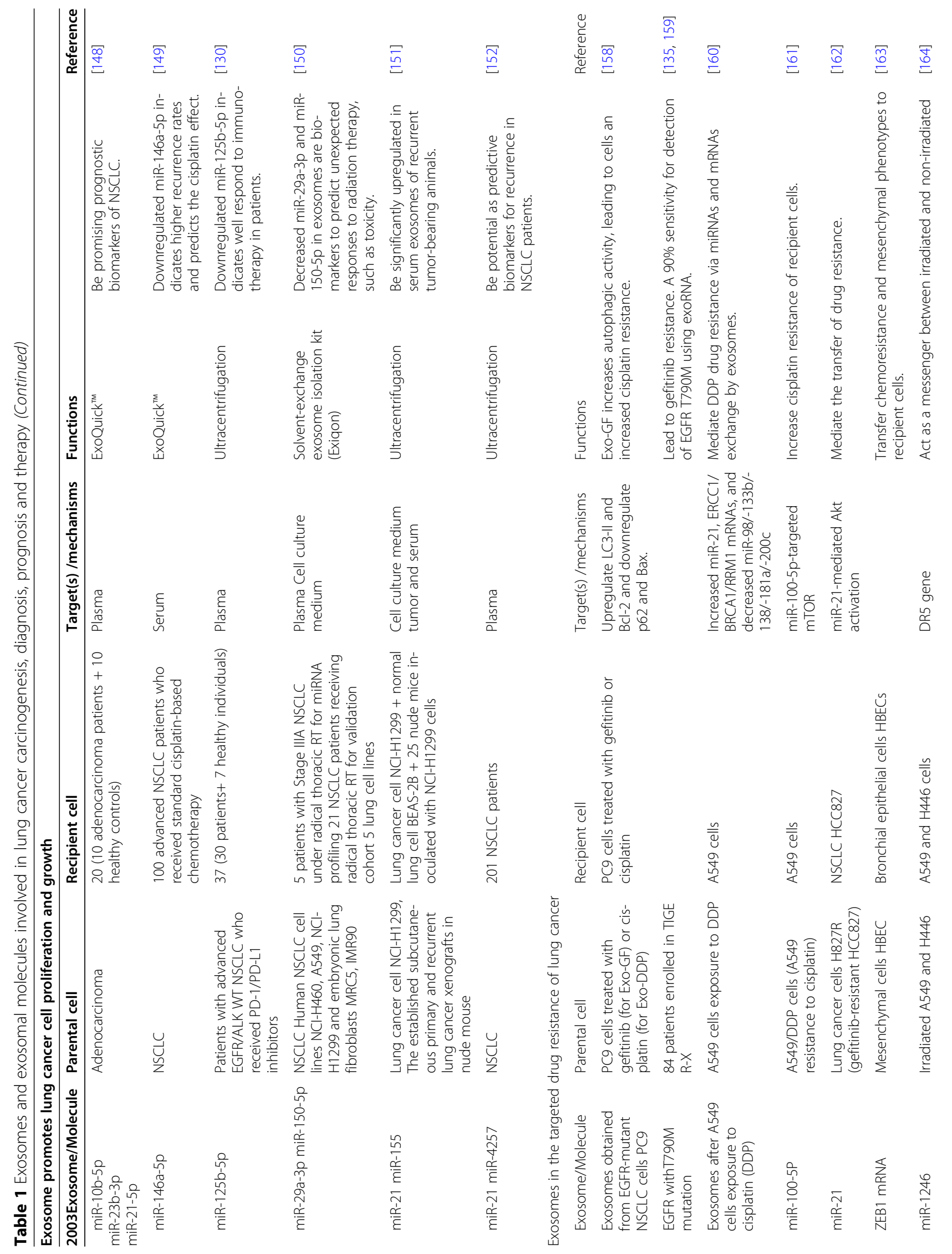




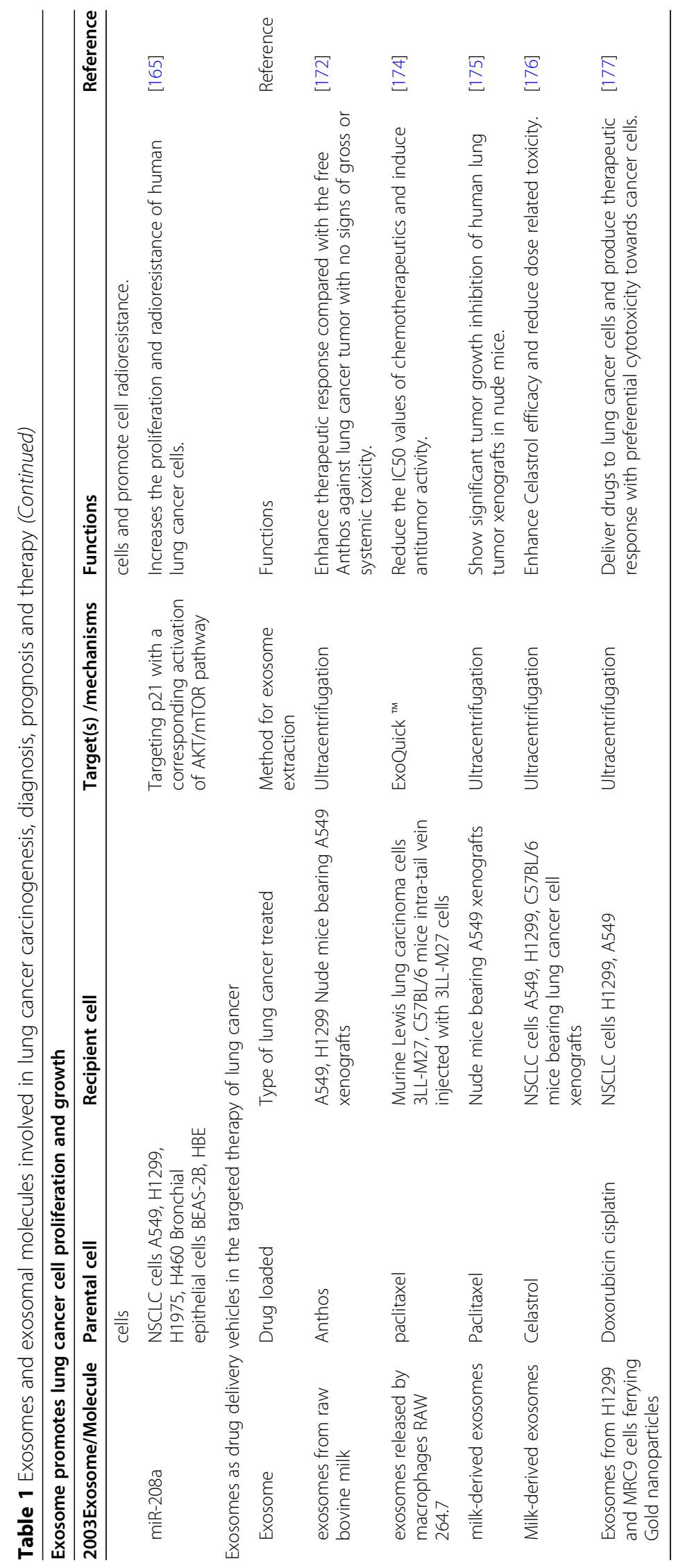




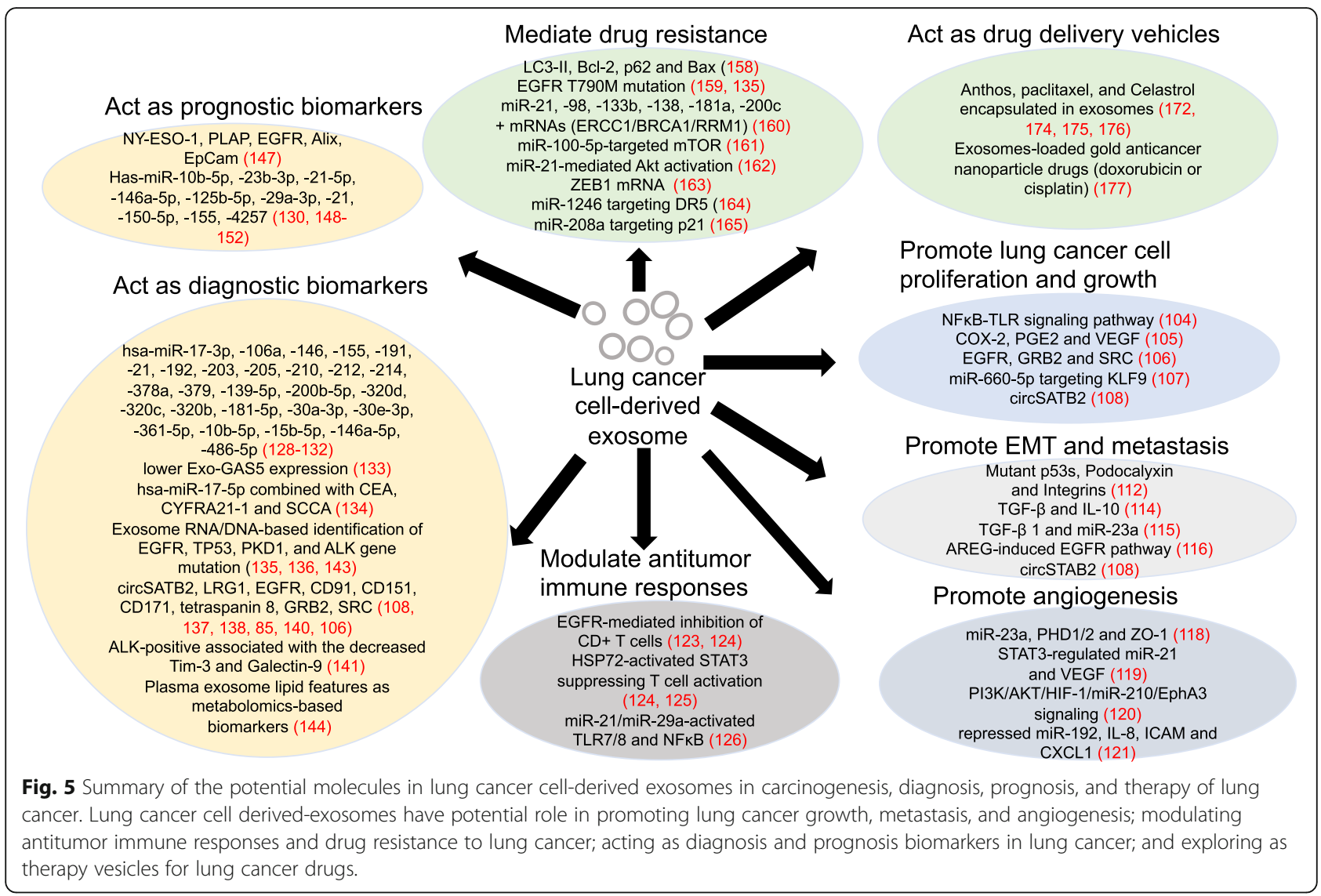

\section{Exosome promotes lung cancer growth and metastasis}

LCCDEs can affect lung cancer progression by regulating the physiological functions of surrounding tissue cells and microenvironment. LCCDEs induce mesenchymal stem cell (MSC) transformation into a pro-inflammatory phenotype via NFKB-TLR signaling pathway to promote MSCs getting tumor supportive characteristics [104]. The induced COX-2 expression in lung cancer cells is transferred to other cells by exosomes, which leads to an increased PGE2 and VEGF production and affects the microenvironments, including COX-2-involved inflammatory reactions [105]. Proteins associated with signal transduction, including EGFR, GRB2 and SRC, are enriched in NSCLC exosomes and actively regulate recipient cells proliferation [106]. High levels of miR-660-5p in NSCLC exosomes promote NSCLC progression by targeting KLF9 [107]. circSATB2 can be transferred by exosomes and then promotes the NSCLC cells proliferation and metastasis, as well as induces abnormal proliferation in normal human bronchial epithelial cells [108].

Metastasis is a critical phase of tumor progression and major cause of cancer mortality, which is related to a variety of mechanisms and involves multiple steps [11]. Different types of metastatic cancer cells are significantly different in organ tropism, which is highly associated with TDEs integrins [96]. The main sites of lung cancer metastasis are brain, adrenal gland, bone and liver [155]. LCCDEs, as carriers of information transmission, can increase tumor cell invasiveness by promoting formation of the PMN microenvironment $[11,156]$. Recently, it has been found that tumor-associated fibroblast behavior including pro-invasive extracellular matrix (ECM) deposition fosters cancer cell migration and invasion [157]. Mutant p53s in NSCLC cells modulate exosomal podocalyxin expression to impact integrin trafficking in fibroblasts and promote deposition of a highly ECM to create a microenvironment supportive of tumor cell metastasis [109]. There is a synergistic interaction between invadopodia biogenesis and exosome secretion with consequent matrix degradation and overall aggressive behavior in promoting cancer cell invasiveness [158]. TGF- $\beta$ and IL-10 in LCCDEs enhance tumor cells rapid growth and migration [110]. Also, TGF$\beta 1$ and miR-23a in LCCDEs are involved in the EMT, which is an important process before the tumor cells metastasis [111]. NSCLC exosomal Amphiregulin (AREG) induce activation of EGFR pathway in pre-osteoclasts to trigger a vicious cycle in osteolytic bone metastasis [112]. It is certainly critical for future work to better dissect how LCCDEs cargoes serve as a novel cellular communication to regulate lung cancer progression, which can help to elucidate the mechanism of lung cancer development. 


\section{Exosome promotes angiogenesis during lung carcinogenesis}

Angiogenesis is vital for tumor growth since tumor vessels are the important nutrient sources for tumor cells [159]. Exosomal miR-23a from hypoxic lung cancer cells can increase angiogenesis and vascular permeability [113]. LCCDEs miR-21, regulated by STAT3, enhances VEGF level to promote tumor angiogenesis and induce malignant transformation of bronchial epithelial cells [114]. LCCDEs miR-210 participates in PI3K/AKT/HIF1/miR-210/EphA3 signaling to promote tumor angiogenesis [115]. A repressed miR-192 in LCCDEs induces angiogenesis and associates with high metastatic activity of bone [116]. All of these indicate that LCCDEs can promote angiogenesis to facilitate lung carcinogenesis.

\section{Exosome modulates antitumor immune responses during lung carcinogenesis}

LCCDEs can affect the immune cells function in the tumor microenvironment. TDE promotes tumor progression by reprogramming immune cell functions and helps immune escape by transferring specific proteins and RNA into the recipient cells [99, 160]. LCCDEs EGFR induce tolerogenic dendritic cells and tumor antigen-specific regulatory $\mathrm{T}$ cells (Treg) to inhibit antitumor function of CD8+ T cells and thus promote lung cancer growth $[117,118]$. LCCDEs HSP72 can activate the Stat3-dependent immunosuppressive effect of MDSCs (myeloid-derived suppressor cells) to suppress T cell activation $[118,119]$. LCCDEs miR-21 and miR-29a can activate Toll-like receptors 7 (TLR7) and 8 (TLR8) on immune cells to activate $\mathrm{NFKB}$ and prometastatic inflammatory response, ultimately leading to tumor growth and metastasis [120].

\section{Exosomal contents as diagnostic or prognostic biomarkers of lung cancer}

Liquid biopsy, which is based on detection of tumorrelated biomarkers from body-related fluids, represents a minimally invasive and more comprehensive option for tumor early detection and investigation. In clinics, tissue collection is the standard practice for lung cancer diagnosis. However, this method is insufficient to present a complete picture of disease state due to the limited amount and times of tissue collection, and frequent tumor heterogeneity. It may not be sufficient to provide the global disease status, especially in the era of precision and personal medicine. Hence, alternative routes of diagnosis are being explored. LCCDEs contain potential biomarkers for lung cancer diagnosis (Table 1 and Fig. 5). The first study of exosomes in lung cancer shows that exosomes can be isolated from pleural effusions of lung cancer patients [161]. Remarkably, some researchers have succeeded in discovering circulating exosomal miRNAs for their diagnostic value in lung cancer. It has been reported that 12 exosomal miRNAs are overexpressed in blood of lung cancer patients compared with control samples (hsa-miR-17-3p/-21/-106a/-146/155/-191/-192/-203/-205/-210/-212/-214) [121]. Another report has showed that four exosomal miRNAs (hsa-miR-378a/-379/-139-5p/-200b-5p) are putative diagnostic markers in plasma samples of lung adenocarcinoma patients [122]. Exosomal miRNA expression profile is significantly altered in NSCLC patients compared with normal controls, as miR-320d, $-320 c$, and $-320 b$ are identified as potential biomarkers for predicting the efficacy of immunotherapy in advanced NSCLCs [123]. Tumor-derived exosome miRNAs (AD-specific miR181-5p/miR-30a-3p/miR-30e-3p/miR-361-5p, and SCCspecific $\mathrm{miR}-10 \mathrm{~b}-5 \mathrm{p} / \mathrm{miR}-15 \mathrm{~b}-5 \mathrm{p} / \mathrm{miR}-320 \mathrm{~b})$ may be highly sensitive and noninvasive biomarkers for NSCLC early diagnosis [124]. Serum exosome miRNAs (miR146a-5p/miR-486-5p) might be preferable biomarkers for NSCLC early diagnosis [125]. The lower expression of noncoding RNA growth arrest-specific transcript 5 (GAS5) in circulating exosomes (Exo-GAS5) could be a noninvasive blood-based tumor marker for early-stage NSCLC identification [126]. The expression of exosomal miR-17-5p, in combination with three circulating tumor markers CEA, CYFRA21-1and SCCA, is significantly higher in NSCLC patients than in healthy controls [127]. Overexpressed circSATB2 in serum exosomes is highly sensitive and specific biomarker for NSCLC diagnosis [108]. Exosomal RNA and DNA have been demonstrated in identification of EGFR mutations of lung tumor origin $[128,129]$. The leucine-rich a2-glycoprotein (LRG1) is found to be expressed at higher levels both in urinary exosomes and lung tissue of NSCLC patients [130]. Plasma exosome EGFR expression levels are remarkably different between lung cancer patients and normal controls [131]. Serum exosome CD91 is identified as a lung adenocarcinoma specific marker [85]. The Extracellular Vesicle Array (EV Array) to phenotype lung cancerrelated proteins in plasma exosomes may be a simple, minimal invasive tool [162], by which exosomal proteins CD151, CD171 and tetraspanin 8 are found to be higher in lung cancer patients of all histological subtypes [132]. NSCLC exosomal proteome has identified the enriched protein cargoes such as EGFR, GRB2 and SRC for lung cancer early detection [106]. ALK-positive NSCLC patients shows a decreased plasma exosome Tim-3 and Galectin-9 levels [133], which are biomarkers for response to first generation ALK-TKIs [163]. Recently, plasma-derived exosome DNA has been successfully used in clinical genetic test with TP53, EGFR, PKD1, and ALK as the top 4 mutated genes in advanced lung adenocarcinoma patients [134]. Consistent differences in the lipid profiles could reflect the altered expression of 
many lipid metabolic genes evident in lung tumors. Plasma exosome lipid features as metabolomics-based biomarkers successfully distinguish early stage lung cancer patient from healthy individuals [135]. Exosome heterogeneity can also be conceptualized according to its size. Recent studies have shown that larger exosomes and smaller exosomes exhibit different properties and may have different functions [164]. In particular, the size distribution of exosomes derived from humoral source is different between patients and healthy controls, indicating the importance of size-dependent analysis of exosomes [165]. Therefore, using the size distribution of exosomes as a potential index is helpful for the diagnosis of diseases. A simple, rapid and economical method to reflect the size of exosomes has a broad application prospect in the future. These data (Table 1 and Fig. 5) suggest that development of novel exosome biomarkers for lung cancer diagnosis will be important for enhancing patient outcome and survival.

Exosomal components can be used as non-invasive prognostic biomarkers of lung cancer [136]. Exosome membrane-bound proteins NY-ESO-1, PLAP, EGFR, Alix and EpCam are correlated to NSCLC overall survival (OS), indicating these proteins as strong prognostic biomarkers [136]. The elevated levels of exosomal miR-10b-5p, miR23b-3p and miR-21-5p are associated with poor OS and are potential prognostic biomarkers of NSCLC [137]. Downregulation of serum exosome miR-146a-5p indicates a poor progression free survival (PFS) and predicts the cisplatin effect on NSCLC [138]. NSCLC plasma exosome miR-125b$5 \mathrm{p}$ as T-cell suppressor is downregulated during the treatment, indicating the increased $\mathrm{T}$-cell function and well respond to immunotherapy in patients [123]. The decreased expression of miR-29a-3p and miR-150-5p in secreted exosomes are biomarkers that correlates with the delivered radiation therapy dose and eventually help predict unexpected responses to radiation therapy, such as toxicity [139]. miR-21 and miR-155 are significantly upregulated in recurrent tumors compared to primary tumors, which are also upregulated in serum exosomes of recurrent tumorbearing animals [140]. The increased expression of plasma exosome miR-21 and miR-4257 has potential as a predictive biomarker for recurrence in NSCLC patients [141]. All these previous findings are quite encouraging (Table 1 and Fig. 5), representing a novel and less invasive option for prognosis of lung cancer.

Currently, exploring biomarkers in LCCDEs is still at a pre-clinical phase. Although the investigations show promising results for their application in screening programs or as prognostic/predictive biomarkers, there exhibits hurdle for the clinical translation. The main challenges are lack of reliable cutoffs and great variability among the studies. Moreover, no established tool has been approved for exosome isolation of clinical samples. Finally, large prospective clinical trials are mandatory to provide evidence of their clinical utility. Nonetheless, should these and other issues be resolved, LCCDEs may account for promising lung cancer biomarkers in the near future.

\section{Exosomes in the targeted drug resistance of lung cancer}

With the development of molecular biology and tumor genetics, the targeted therapy has become a hot topic, which can guide therapeutic decision and thus reduce morbidity and mortality. Among more than 300 mutations in lung cancer, only a few of these genes such as EGFR, ALK, c-met, ROS1can promote or drive the lung tumorigenesis $[166,167]$. More recently, treatment with the immune checkpoint inhibitors targeting axis such as programmed death protein 1 (PD-1) and its ligand (PD-L1) have revolutionized a large proportion of NSCLC patient management [168]. The EGFR mutations reveal a potential responsiveness of NSCLC to TKIs [169]. Drug resistance is a major hurdle in cancer therapy. Exosomes originating from either tumor cells or cancer associated fibroblasts (CAFs) can mediate resistance to chemotherapy, radiotherapy and targeted therapy [170]. Exosomes are involved in inducing lung cancer treatment resistance to concurrent chemotherapy and TKIs. It has been shown that cisplatin sensitivity was significantly reduced when lung cancer cells were treated with cisplatin combined with exosomes derived from gefitinibtreated lung cancer cells, underlining the importance of exosomes in mediating antagonistic effects of cisplatin and gefitinib therapy [142]. T790M mutation is found in patients treated with EGFR-TKIs which leads to gefitinib resistance [143]. Exosomal RNA is used to detect EGFR T790M and activating EGFR mutations, with the sensitivity of $90 \%$ and $98 \%$ respectively [128]. It has been found that the exosomes released by A549 cells during cisplatin exposure decrease the sensitivity of non-treated A549 cells to cisplatin through several miRNAs (increased expression level of miR-21 while decreased expression levels of miR-98/ 133b/138/181a/200c) and mRNAs (increased expression levels of ERCC1/BRCA1/RRM1) exchange by exosomes via cell-to-cell communication [144]. Several molecules in LCCDEs are involved in the targeted drug resistance of lung cancer (Table 1 and Fig. 5). Cisplatin-resistant LCCD Es increase cisplatin resistance of recipient cells in exosome miR-100-5p-dependent manner with mTOR as its potential target [145]. Exosome-mediated gefitinib resistance in lung cancer cells is via delivery of miR-21 to activate Akt [146]. Exosomes derived from mesenchymal and oncogenically transformed lung cells can transfer chemo-resistance and mesenchymal phenotypes to recipient cells via exosomal ZEB1 mRNA [147]. Upregulation of miR-1246 and miR208a as prognostic biomarker, are associated with radiotherapy resistance and high proliferation of the tumor by targeting DR5 and p21 respectively [148, 149]. Although the detailed mechanism of exosome-mediated drug 
resistance remains unclear, inhibition of LCCDEs formation and release may present a novel therapeutic strategy for lung cancer. Furthermore, it is possible to identify drug targeted therapy resistance of lung cancer patients via screening specific molecules in LCCDEs.

\section{Exosomes as drug delivery vehicles in the targeted therapy of lung cancer}

Therapeutic Deliverable Exosomes are emerging as promising drug delivery agents because of their natural intercellular communication role, excellent biocompatibility, low immunogenicity, low toxicity, long blood circulation ability, biodegradable characteristics and their ability to cross various biological barriers $[48,54]$. Homotypic adhesion molecules on exosome membrane endow exosomes with strong preferential binding to source cells [171]. Tetraspanin CD9 and CD81 on exosome membrane can promote direct membrane fusion between exosomes and cells, allowing the exosomal cargo transportation [172]. CD55 and CD59 on exosome membrane can protect exosome from complement attack and increase its stability in circulation [173]. Moreover, high expression level of CD47 on exosome membrane leads to exosome resistance to phagocytosis by monocytes and macrophages $[174,175]$.

However, making exosomes with satisfactory cancertargeting ability and controlling encapsulated drug release is highly challenging. Exosomes are engineered to carry anticancer therapeutics by active (sonication, electroporation, or freeze-thaw cycles) or passive (simple incubation with exosomes) drug-loading approaches [150, 176]. Molecules such as lncRNAs, miRNAs, and siRNAs can also be added through genome engineering of the donor cells, which helps in de novo production and incorporation of these molecules into exosomes [177]. The paclitaxelloaded exosome drug delivery system reduces the IC50 values of chemotherapeutics and induces antitumor activity in mouse lung cancer models [151]. Drugs (Anthos/ paclitaxel/Celastrol) encapsulated in exosomes show enhanced therapeutic effect in lung cancer xenografts nude mice [150, 152, 153]. Another research has also shown that exosomes loaded with gold anticancer nanoparticle drugs (doxorubicin/cisplatin) are able to deliver drugs to lung cancer cells and produce therapeutic response [154].

One biological strategy to equip exosomes with targeting properties involves incorporating targeting peptides or proteins by inducing their expression in exosome donor cells [178]. In addition to ligand-mediated targeting, magnetic drug targeting provides an alternative method to improve the level of therapeutic efficacy [179]. However, the targeting efficiency of a single ligand is not satisfied because of receptor saturation phenomenon [180]. To overcome these limitations, dual ligand-based active targeting strategies are developed to enable the engineered exosomes with ability of both specific accumulation and improved drug release at the target tumor site [181]. Recently, a synthetic exosome not only preserves the intrinsic functionalities of native exosome, but also gains multiple abilities for efficient tumor targeting via dual ligand-mediated endocytosis, a controlled release, and thermal therapy at target tumor sites [182]. Tumor-specific targeting of drug-loaded nanoparticles (NPs) can be implemented by both passive and active strategies. Passive targeting exploits the enhanced permeation and retention (EPR) effect of small size NPs (50-200 nm) through the abnormal tumor vasculature to accumulate into tumor sites [183]. Active targeting of NPs relies on PEGylation and surface modification of targeting ligands to efficiently increase the targeting specificity to tumors [184]. However, the synthetic NPs exhibits rapid clearance by the mononuclear phagocyte system (MPS) during in vivo circulation. Exosome-coated NPs can reduce the MPS uptake with significant advantages in terms of prolonged blood circulation time, optimal biocompatibility, and enhanced targeting effect [174, 182]. TDE-coated PLGA NPs, using microfluidic sonication approach to fabricate biomimetic NPs, show superior homotypic targeting efficacy and immune evasion [185]. Another report shows an exosomecoated PLGA NPs loaded with DOX achieve efficiently targeted chemotherapy of triple-negative breast cancer [186].

Current studies indicate that exosomes are ideal drug delivery vehicles to protect the enclosed drugs from degradation or damage due to their lipid bilayer membrane and nanoscale size. Future applications for exosome drug carriers include both allogeneic and autologous applications, the latter can avoid potential immune responses [187]. Multipotent stem cells (MSCs)-derived exosomes are thought to possess limited immunogenicity due to low expression of co-stimulatory molecules, such as class I major histocompatibility complex (MHC) molecules, making them suitable for allogeneic transplantation [187]. It is unclear whether allogeneic exosome sources have the potential to be streamlined and developed as off-the-shelf products used for future drug delivery applications. Isolation of distinct exosome subpopulations that display favorable transport properties has proved challenging with current techniques. The versatile designer exosome combined with synthetic materials aims to be used in individualized precise cancer therapy in the future. And the research endpoint in experimental diagnostics/prognostics/ therapeutics of lung cancer is to be translated into clinical applications. Clinical Trials play the key role on translational application of exosome-based diagnostics/prognostics/therapeutics into clinics. A December $7^{\text {th }} 2020$ search of https://clinicaltrials.gov/ct2/search shows about 18 studies related to exosomes and lung cancer (Table 2). Notably, although most of the studies are related to development of exosome-based diagnosis/prognosis, one study investigates the therapeutic aspects. A dendritic cell-derived exosome (Dex)-based clinical trial in phase II examines the use of 
Li et al. Molecular Cancer

(2021) 20:22

Page 17 of 22

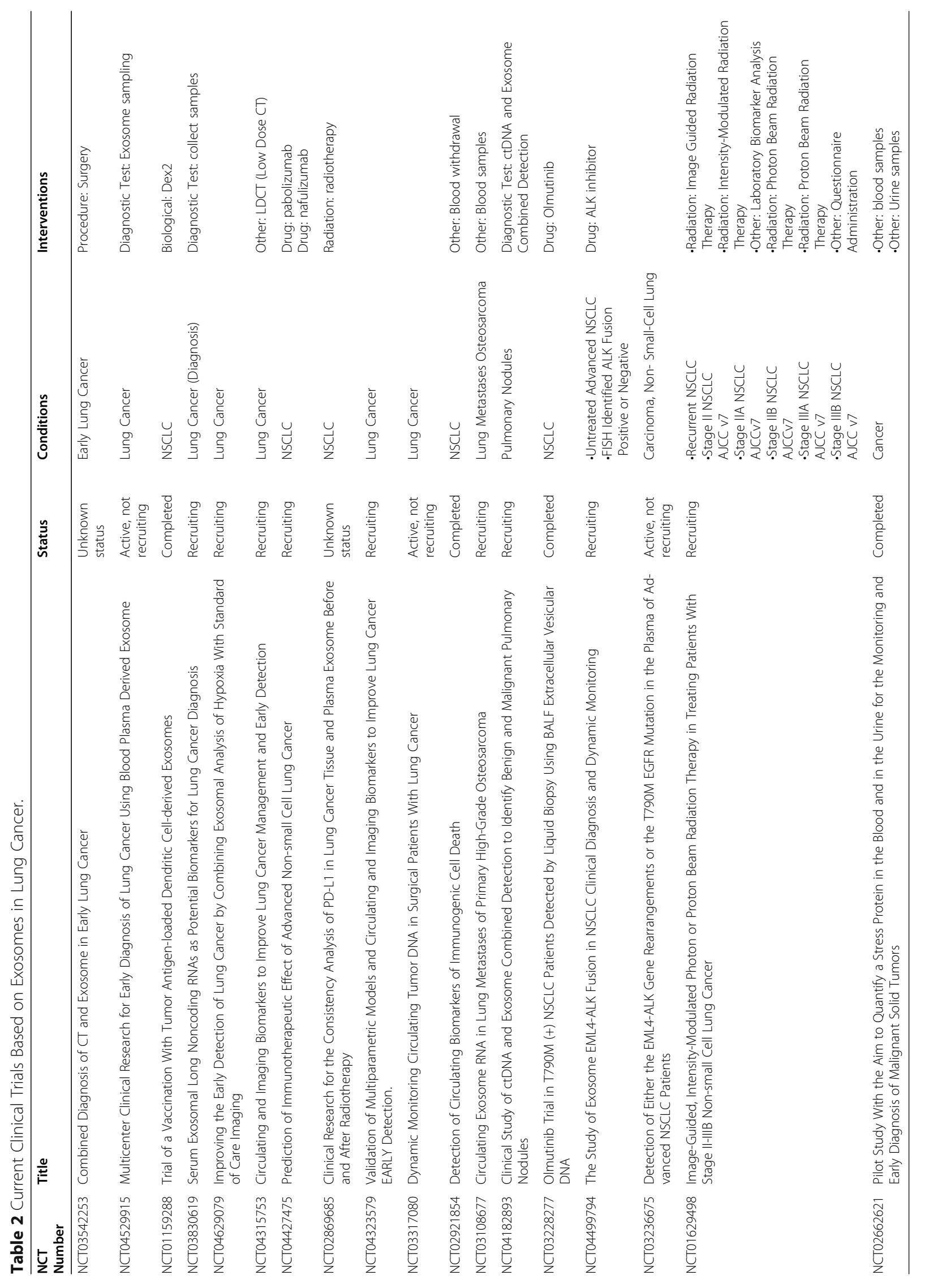


Dex as vaccine to impart immunotherapy in combination with metronomic cyclophosphamide (mCTX) therapy in patients with lung cancer (NCT01159288) (Table 2).

\section{Conclusion and perspectives}

LCCDEs participate in the lung cancer progression. With deep investigation of LCCDEs-mediated role and signal pathways, the mechanism of lung carcinogenesis can be further elucidated. The highlights of exosome biomarkers include that they contain stable sources of tumor-derived genetic material; Exosome number is higher in patients than in healthy controls; Exosomal miRNAs can discriminate healthy individual from patients, early stage from advanced stage, and recurrence from non-recurrence; Exosomal RNA and DNA have a higher sensitivity in detection of somatic mutations. Accumulating evidence suggests that exosome biomarker has a prospective use in lung cancer diagnosis and prognosis. Lung cancer is a disease worthy of precise and personalized medical treatment. Due to the unique biological characters of exosomes, delivery of therapeutic agents through exosomes is a novel approach that holds a great future in medicine. We summarize the pivotal role of exosomes in lung carcinogenesis, and highlights the exemplary capacity of exosomes to be used as diagnostic, prognostic, and therapeutic agents in lung cancer (Table 1 and Fig. 5).

However, a number of associated challenges must be resolved before exosome-based diagnosis/prognosis and delivery systems are applied in clinical settings. The first and most important limitation is related to exosome isolation and thorough characterization. The lack of standardized exosome isolation techniques, storage methods, and appropriate quality controls has hampered further translation and clinical-grade exosome production. In addition, bulk and scalable exosomes manufacturing remains a major hurdle for clinical translation and production cost control. The biofluids availability and exosomes abundance in biofluids varies frequently. Hence, a standardized method for exosome isolation is warranted to ensure a consistent and repeatable exosome supply. The exosome preparation should also be of high quality, homogenous in nature, and free from other cellular vesicular contamination. Meanwhile, challenge for development of exosome biomarkers is lack of large prospective studies to provide evidence that exosome liquid biopsy can be a valid alternative to tumor tissue biopsy. The foremost challenge associated with biological-origin exosome therapeutic system is maintenance of good manufacturing practices. Hence, the standardized protocols to ensure consistent production of exosomes will be needed before exosomebased therapy enters clinical practice. Although exosomemediated therapy as well as diagnosis and prognosis appear promising, more research needs to be done before exosome is incorporated into clinical applications.

\section{Abbreviations}

AD: Adenocarcinoma; AFM: Atomic Force Microscopy; ALIX : Apoptosis-linked gene 2-interacting protein X; AREG: Amphiregulin; CAFs: Cancer associated fibroblasts; Dex: Dendritic cell-derived exosome; DLS: Dynamic light scattering; EPR: The enhanced permeation and retention; ECM: Extracellular matrix; EMT: Epithelial-mesenchymal transition; ESEs: Early sorting endosome; Exo-GAS5: Growth arrest-specific transcript 5 (GAS5) in circulating exosomes; ESCRT: Endosomal sorting complexes required for transport;

ETS: Environmental tobacco smoke; EVs: Extracellular vesicles; LCC: Large cell carcinoma; LCCDEs: Lung cancer cell-derived exosomes; LCNS: Lung cancer in never smokers; LRG1: Leucine-rich a2-glycoprotein; LSEs: Late sorting endosome; MDSCs: Myeloid-derived suppressor cells; MHC: Major histocompatibility complex; MSCs: Multipotent stem cells; MPS: Mononuclear phagocyte system; MSC: Mesenchymal stem cell; MVBs: Multivesicular body; NK: Natural killer; NNK: 4-(methylnitrosamino)-1(3-pyridyl)-1-butanone; NSCL C: Non-small cell lung carcinoma; NTA: Nanoparticle Tracking Analysis; NPs: Drug-loaded nanoparticles; OS: Overall survival; PD-1 and PD-

L1: Programmed death protein 1 and its ligand; PFS: Progression free survival; PM 2.5 : Particulate matter 2.5; SCC: Squamous cell carcinoma; SCLC: Small-cell lung carcinoma; TDEs: Tumor-derived exosomes;

TEM: Transmission Electron Microscopy; TLR7 and TLR8: Toll-like receptors 7 and 8; Treg: Regulatory T cells; TRK-A3: Tyrosine receptor kinase A3;

TRPS: Tunable Resistive Pulse Sensing; TSG101: Tumor susceptibility gene 101; UF: Ultrafiltration

\section{Acknowledgments}

Not applicable.

\section{Authors' contributions}

MYL, LZL and MD designed the review. MYL and $L Z L$ drafted the manuscript and prepared the figures. $L Z L$ and MD revised the manuscript. All authors read and approved the final manuscript.

\section{Funding}

This study was supported by grants from the Guangdong Bioland Laboratory (Guangzhou Regenerative Medicine and Health Guangdong Laboratory) grand 1102101203, National Natural Science Foundation of China 82072584 and 81570784, and Shenzhen Municipal Science and Technology Program JCYJ20150324141711688.

Availability of data and materials

All data generated or analyzed during this study are included in this published article.

Ethics approval and consent to participate Not applicable.

Consent for publication

Not applicable

\section{Competing interests}

The authors declare no competing interests.

Received: 25 September 2020 Accepted: 12 January 2021

Published online: 27 January 2021

\section{References}

1. Bray F, Ferlay J, Soerjomataram I, Siegel RL, Torre LA, Jemal A. Global cancer statistics 2018: GLOBOCAN estimates of incidence and mortality worldwide for 36 cancers in 185 countries. CA Cancer J Clin. 2018;68(6):394-424.

2. Zappa C, Mousa SA. Non-small cell lung cancer: current treatment and future advances. Transl Lung Cancer Res. 2016;5(3):288-300.

3. Kenfield SA, Wei EK, Stampfer MJ, Rosner BA, Colditz GA. Comparison of aspects of smoking among the four histological types of lung cancer. Tob Control. 2008;17(3):198-204.

4. Muscat JE, Stellman SD, Zhang ZF, Neugut Al, Wynder EL. Cigarette smoking and large cell carcinoma of the lung. Cancer Epidemiol Biomark Prev. 1997; 6(7):477-80

5. Couraud S, Zalcman G, Milleron B, Morin F, Souquet PJ. Lung cancer in never smokers--a review. Eur J Cancer. 2012;48(9):1299-311. 
6. Bade BC, Dela Cruz CS. Lung Cancer 2020: Epidemiology, Etiology, and Prevention. Clin Chest Med. 2020;41(1):1-24.

7. Chen WW, Ruiz BA, Hsieh MC, Wu XC, Ries LA, Lewis DR. Analysis of stage and clinical/prognostic factors for lung cancer from SEER registries: AJCC staging and collaborative stage data collection system. Cancer. 2014; 120(Suppl 23):3781-92.

8. Pirker R. Conquering lung cancer: current status and prospects for the future. Pulmonology. 2020.

9. Cheng TY, Cramb SM, Baade PD, Youlden DR, Nwogu C, Reid ME. The International Epidemiology of Lung Cancer: Latest Trends, Disparities, and Tumor Characteristics. J Thorac Oncol. 2016;11(10):1653-71.

10. Kalluri R, LeBleu VS. The biology, function, and biomedical applications of exosomes. Science. 2020;367:6478.

11. Wortzel I, Dror S, Kenific CM, Lyden D. Exosome-Mediated Metastasis: Communication from a Distance. Dev Cell. 2019:49(3):347-60.

12. Akopyan $\mathrm{G}$, Bonavida B. Understanding tobacco smoke carcinogen NNK and lung tumorigenesis. Int J Oncol. 2006;29(4):745-52.

13. Stepanov I, Upadhyaya P, Carmella SG, Feuer R, Jensen J, Hatsukami DK, et al. Extensive metabolic activation of the tobacco-specific carcinogen 4(methylnitrosamino)-1-(3-pyridyl)-1-butanone in smokers. Cancer Epidemiol Biomark Prev. 2008;17(7):1764-73.

14. Wakelee HA, Chang ET, Gomez SL, Keegan TH, Feskanich D, Clarke CA, et al. Lung cancer incidence in never smokers. J Clin Oncol. 2007:25(5):472-8.

15. Janerich DT, Thompson WD, Varela LR, Greenwald P, Chorost S, Tucci C, et al. Lung cancer and exposure to tobacco smoke in the household. N Engl J Med. 1990;323(10):632-6.

16. Hackshaw AK, Law MR, Wald NJ. The accumulated evidence on lung cancer and environmental tobacco smoke. BMJ. 1997;315(7114):980-8.

17. Hu D, Jiang J. PM2.5 Pollution and Risk for Lung Cancer: A Rising Issue in China. J Environ Prot. 2014;5:731-8.

18. Fajersztajn L, Veras M, Barrozo LV, Saldiva P. Air pollution: a potentially modifiable risk factor for lung cancer. Nat Rev Cancer. 2013;13(9):674-8.

19. Lu F, Xu D, Cheng Y, Dong S, Guo C, Jiang X, et al. Systematic review and meta-analysis of the adverse health effects of ambient PM2.5 and PM10 pollution in the Chinese population. Environ Res. 2015;136:196-204.

20. Li J, Li WX, Bai C, Song Y. Particulate matter-induced epigenetic changes and lung cancer. Clin Respir J. 2017;11(5):539-46.

21. Raaschou-Nielsen O, Beelen R, Wang M, Hoek G, Andersen ZJ, Hoffmann B, et al. Particulate matter air pollution components and risk for lung cancer. Environ Int. 2016:87:66-73.

22. Chen W, Zheng R, Baade PD, Zhang S, Zeng H, Bray F, et al. Cancer statistics in China, 2015. CA Cancer J Clin. 2016;66(2):115-32.

23. Li MY, Liu LZ, Li W, Ng CSH, Liu Y, Kong AWY, et al. Ambient fine particulate matter inhibits 15-lipoxygenases to promote lung carcinogenesis. J Exp Clin Cancer Res. 2019;38(1):359

24. Gharibvand L, Shavlik D, Ghamsary M, Beeson WL, Soret S, Knutsen R, et al. The Association between Ambient Fine Particulate Air Pollution and Lung Cancer Incidence: Results from the AHSMOG-2 Study. Environ Health Perspect. 2017:125(3):378-84.

25. Pope CA 3rd, Burnett RT, Thun MJ, Calle EE, Krewski D, Ito K, et al. Lung cancer, cardiopulmonary mortality, and long-term exposure to fine particulate air pollution. JAMA. 2002;287(9):1132-41.

26. Raaschou-Nielsen O, Pedersen M, Stafoggia M, Weinmayr G, Andersen ZJ, Galassi C, et al. Outdoor air pollution and risk for kidney parenchyma cancer in 14 European cohorts. Int J Cancer. 2017;140(7):1528-37.

27. Turner MC, Chen Y, Krewski D, Calle EE, Thun MJ. Chronic obstructive pulmonary disease is associated with lung cancer mortality in a prospective study of never smokers. Am J Respir Crit Care Med. 2007;176(3):285-90.

28. Yang P, Sun Z, Krowka MJ, Aubry MC, Bamlet WR, Wampfler JA, et al. Alpha1-antitrypsin deficiency carriers, tobacco smoke, chronic obstructive pulmonary disease, and lung cancer risk. Arch Intern Med. 2008;168(10): 1097-103.

29. Hubbard R, Venn A, Lewis S, Britton J. Lung cancer and cryptogenic fibrosing alveolitis. A population-based cohort study. Am J Respir Crit Care Med. 2000;161(1):5-8.

30. Antoniou KM, Tomassetti S, Tsitoura E, Vancheri C. Idiopathic pulmonary fibrosis and lung cancer: a clinical and pathogenesis update. Curr Opin Pulm Med. 2015;21(6):626-33.

31. Harding JL, Andes LJ, Gregg EW, Cheng YJ, Weir HK, Bullard KM, et al. Trends in cancer mortality among people with vs without diabetes in the USA, 1988-2015. Diabetologia. 2020;63(1):75-84.
32. Zhu H, Zhang S. Body mass index and lung cancer risk in never smokers: a meta-analysis. BMC Cancer. 2018;18(1):635.

33. Patel AV, Carter BD, Stevens VL, Gaudet MM, Campbell PT, Gapstur SM. The relationship between physical activity, obesity, and lung cancer risk by smoking status in a large prospective cohort of US adults. Cancer Causes Control. 2017:28(12):1357-68.

34. Kabat GC, Kim M, Hunt JR, Chlebowski RT, Rohan TE. Body mass index and waist circumference in relation to lung cancer risk in the Women's Health Initiative. Am J Epidemiol. 2008;168(2):158-69.

35. Spitz MR, Etzel CJ, Dong Q, Amos Cl, Wei Q, Wu X, et al. An expanded risk prediction model for lung cancer. Cancer Prev Res (Phila). 2008;1 (4):250-4.

36. Cassidy A, Myles JP, van Tongeren M, Page RD, Liloglou T, Duffy SW, et al. The LLP risk model: an individual risk prediction model for lung cancer. Br J Cancer. 2008;98(2):270-6.

37. Matakidou A, Eisen T, Houlston RS. Systematic review of the relationship between family history and lung cancer risk. Br J Cancer. 2005;93(7):825-33.

38. Wang Y, McKay JD, Rafnar T, Wang Z, Timofeeva MN, Broderick P, et al. Rare variants of large effect in BRCA2 and CHEK2 affect risk of lung cancer. Nat Genet. 2014;46(7):736-41.

39. Hwang SJ, Cheng LS, Lozano G, Amos Cl, Gu X, Strong LC. Lung cancer risk in germline p53 mutation carriers: association between an inherited cancer predisposition, cigarette smoking, and cancer risk. Hum Genet. 2003;113(3): 238-43.

40. Sanders BM, Jay M, Draper GJ, Roberts EM. Non-ocular cancer in relatives of retinoblastoma patients. Br J Cancer. 1989:60(3):358-65.

41. Swift M, Chase C. Cancer in families with xeroderma pigmentosum. J Natl Cancer Inst. 1979;62(6):1415-21.

42. Takemiya M, Shiraishi S, Teramoto T, Miki Y. Bloom's syndrome with porokeratosis of Mibelli and multiple cancers of the skin, lung and colon. Clin Genet. 1987;31(1):35-44

43. Yamanaka A, Hirai T, Ohtake Y, Kitagawa M. Lung cancer associated with Werner's syndrome: a case report and review of the literature. Jpn J Clin Oncol. 1997;27(6):415-8.

44. Devarakonda S, Morgensztern D, Govindan R. Genomic alterations in lung adenocarcinoma. Lancet Oncol. 2015;16(7):e342-51.

45. ExoCarta. Exosome protein, RNA and lipid database. www.exocarta.org. 2020.

46. Busatto S, Pham A, Suh A, Shapiro S, Wolfram J. Organotropic drug delivery: Synthetic nanoparticles and extracellular vesicles. Biomed Microdevices. 2019;21(2):46.

47. Rana S, Yue S, Stadel D, Zoller M. Toward tailored exosomes: the exosomal tetraspanin web contributes to target cell selection. Int J Biochem Cell Biol. 2012;44(9):1574-84.

48. Boukouris $\mathrm{S}$, Mathivanan $\mathrm{S}$. Exosomes in bodily fluids are a highly stable resource of disease biomarkers. Proteomics Clin Appl. 2015;9(3-4):358-67.

49. Raposo G, Stoorvogel W. Extracellular vesicles: exosomes, microvesicles, and friends. J Cell Biol. 2013;200(4):373-83.

50. Harding CV, Heuser JE, Stahl PD. Exosomes: looking back three decades and into the future. J Cell Biol. 2013;200(4):367-71.

51. Bobrie A, Colombo M, Raposo G, Thery C. Exosome secretion: molecular mechanisms and roles in immune responses. Traffic. 2011;12(12):1659-68.

52. Zhang HG, Grizzle WE. Exosomes and cancer: a newly described pathway of immune suppression. Clin Cancer Res. 2011;17(5):959-64.

53. Kujala P, Raymond CR, Romeijn M, Godsave SF, van Kasteren SI, Wille H, et al. Prion uptake in the gut: identification of the first uptake and replication sites. PLoS Pathog. 2011;7(12):e1002449

54. Batrakova EV, Kim MS. Using exosomes, naturally-equipped nanocarriers, for drug delivery. J Control Release. 2015;219:396-405.

55. Hessvik NP, Llorente A. Current knowledge on exosome biogenesis and release. Cell Mol Life Sci. 2018;75(2):193-208.

56. Blanc L, Vidal M. New insights into the function of Rab GTPases in the context of exosomal secretion. Small GTPases. 2018;9(1-2):95-106.

57. Juan T. Furthauer M. Biogenesis and function of ESCRT-dependent extracellular vesicles. Semin Cell Dev Biol. 2018;74:66-77.

58. Andreu Z, Yanez-Mo M. Tetraspanins in extracellular vesicle formation and function. Front Immunol. 2014;5:442.

59. Skotland T, Sandvig K, Llorente A. Lipids in exosomes: Current knowledge and the way forward. Prog Lipid Res. 2017;66:30-41.

60. Raiborg C, Stenmark $\mathrm{H}$. The ESCRT machinery in endosomal sorting of ubiquitylated membrane proteins. Nature. 2009;458(7237):445-52. 
61. Baietti MF, Zhang Z, Mortier E, Melchior A, Degeest G, Geeraerts A, et al. Syndecan-syntenin-ALIX regulates the biogenesis of exosomes. Nat Cell Biol. 2012;14(7):677-85.

62. Skotland T, Hessvik NP, Sandvig K, Llorente A. Exosomal lipid composition and the role of ether lipids and phosphoinositides in exosome biology. J Lipid Res. 2019;60(1):9-18.

63. Kowal J, Arras G, Colombo M, Jouve M, Morath JP, Primdal-Bengtson B, et al. Proteomic comparison defines novel markers to characterize heterogeneous populations of extracellular vesicle subtypes. Proc Natl Acad Sci U S A. 2016; 113(8):E968-77.

64. van Niel G, D'Angelo G, Raposo G. Shedding light on the cell biology of extracellular vesicles. Nat Rev Mol Cell Biol. 2018;19(4):213-28.

65. Mathieu M, Martin-Jaular L, Lavieu G, Thery C. Specificities of secretion and uptake of exosomes and other extracellular vesicles for cell-to-cell communication. Nat Cell Biol. 2019;21(1):9-17.

66. Li W, Li C, Zhou T, Liu X, Liu X, Li X, et al. Role of exosomal proteins in cancer diagnosis. Mol Cancer. 2017;16(1):145

67. Ogawa Y, Kanai-Azuma M, Akimoto Y, Kawakami H, Yanoshita R. Exosomelike vesicles with dipeptidyl peptidase IV in human saliva. Biol Pharm Bull. 2008;31(6):1059-62.

68. Miyanishi M, Tada K, Koike M, Uchiyama Y, Kitamura T, Nagata S. Identification of Tim4 as a phosphatidylserine receptor. Nature. 2007; 450(7168):435-9.

69. Segura E, Nicco C, Lombard B, Veron P, Raposo G, Batteux F, et al. ICAM-1 on exosomes from mature dendritic cells is critical for efficient naive T-cell priming. Blood. 2005;106(1):216-23.

70. Feng D, Zhao WL, Ye YY, Bai XC, Liu RQ, Chang LF, et al. Cellular internalization of exosomes occurs through phagocytosis. Traffic. 2010;11(5): 675-87.

71. Fitzner D, Schnaars M, van Rossum D, Krishnamoorthy G, Dibaj P, Bakhti M, et al. Selective transfer of exosomes from oligodendrocytes to microglia by macropinocytosis. J Cell Sci. 2011;124(Pt 3):447-58.

72. Tian T, Zhu YL, Zhou YY, Liang GF, Wang YY, Hu FH, et al. Exosome uptake through clathrin-mediated endocytosis and macropinocytosis and mediating miR-21 delivery. J Biol Chem. 2014;289(32):22258-67.

73. Nanbo A, Kawanishi E, Yoshida R, Yoshiyama H. Exosomes derived from Epstein-Barr virus-infected cells are internalized via caveola-dependent endocytosis and promote phenotypic modulation in target cells. J Virol. 2013;87(18):10334-47.

74. Svensson KJ, Christianson HC, Wittrup A, Bourseau-Guilmain E, Lindqvist E, Svensson LM, et al. Exosome uptake depends on ERK1/2-heat shock protein 27 signaling and lipid Raft-mediated endocytosis negatively regulated by caveolin-1. J Biol Chem. 2013;288(24):17713-24.

75. Properzi F, Logozzi M, Fais S. Exosomes: the future of biomarkers in medicine. Biomark Med. 2013;7(5):769-78.

76. Thery C, Ostrowski M, Segura E. Membrane vesicles as conveyors of immune responses. Nat Rev Immunol. 2009;9(8):581-93.

77. Greening DW, Xu R, Ji H, Tauro BJ, Simpson RJ. A protocol for exosome isolation and characterization: evaluation of ultracentrifugation, densitygradient separation, and immunoaffinity capture methods. Methods Mol Biol. 2015:1295:179-209.

78. Konoshenko MY, Lekchnov EA, Vlassov AV, Laktionov PP. Isolation of Extracellular Vesicles: General Methodologies and Latest Trends. Biomed Res Int. 2018;2018:8545347.

79. Momen-Heravi F, Balaj L, Alian S, Trachtenberg AJ, Hochberg FH, Skog J, et al. Impact of biofluid viscosity on size and sedimentation efficiency of the isolated microvesicles. Front Physiol. 2012;3:162.

80. Peterson MF, Otoc N, Sethi JK, Gupta A, Antes TJ. Integrated systems for exosome investigation. Methods. 2015;87:31-45.

81. Thery C, Amigorena S, Raposo G, Clayton A. Isolation and characterization of exosomes from cell culture supernatants and biological fluids. Curr Protoc Cell Biol. 2006; Chapter 3:Unit 322.

82. Tian Y, Gong M, Hu Y, Liu H, Zhang W, Zhang M, et al. Quality and efficiency assessment of six extracellular vesicle isolation methods by nanoflow cytometry. J Extracell Vesicles. 2020;9(1):1697028.

83. Contreras-Naranjo JC, Wu HJ, Ugaz VM. Microfluidics for exosome isolation and analysis: enabling liquid biopsy for personalized medicine. Lab Chip. 2017;17(21):3558-77

84. Liu F, Vermesh O, Mani V, Ge TJ, Madsen SJ, Sabour A, et al. The Exosome Total Isolation Chip. ACS Nano. 2017;11:10712-23.
85. Ueda K, Ishikawa N, Tatsuguchi A, Saichi N, Fujii R, Nakagawa H. Antibodycoupled monolithic silica microtips for highthroughput molecular profiling of circulating exosomes. Sci Rep. 2014;4:6232.

86. Fang S, Tian H, Li X, Jin D, Li X, Kong J, et al. Clinical application of a microfluidic chip for immunocapture and quantification of circulating exosomes to assist breast cancer diagnosis and molecular classification. PLoS One. 2017;12(4):e0175050.

87. Zhou X, Xie F, Wang L, Zhang L, Zhang S, Fang M, et al. The function and clinical application of extracellular vesicles in innate immune regulation. Cell Mol Immunol. 2020.

88. Anderson W, Lane R, Korbie D, Trau M. Observations of Tunable Resistive Pulse Sensing for Exosome Analysis: Improving System Sensitivity and Stability. Langmuir. 2015;31(23):6577-87.

89. Colombo M, Raposo G, Thery C. Biogenesis, secretion, and intercellular interactions of exosomes and other extracellular vesicles. Annu Rev Cell Dev Biol. 2014;30:255-89.

90. Yuana Y, Oosterkamp TH, Bahatyrova S, Ashcroft B, Garcia Rodriguez P, Bertina RM, et al. Atomic force microscopy: a novel approach to the detection of nanosized blood microparticles. J Thromb Haemost. 2010;8(2): 315-23.

91. Pospichalova V, Svoboda J, Dave Z, Kotrbova A, Kaiser K, Klemova D, et al. Simplified protocol for flow cytometry analysis of fluorescently labeled exosomes and microvesicles using dedicated flow cytometer. J Extracell Vesicles. 2015;4:25530

92. Dragovic RA, Gardiner C, Brooks AS, Tannetta DS, Ferguson DJ, Hole P, et al. Sizing and phenotyping of cellular vesicles using Nanoparticle Tracking Analysis. Nanomedicine. 2011;7(6):780-8.

93. Thery C, Witwer KW, Aikawa E, Alcaraz MJ, Anderson JD, Andriantsitohaina R, et al. Minimal information for studies of extracellular vesicles 2018 (MISEV2018): a position statement of the International Society for Extracellular Vesicles and update of the MISEV2014 guidelines. J Extracell Vesicles. 2018;7(1):1535750.

94. Novikova S, Shushkova N, Farafonova T, Tikhonova O, Kamyshinsky R, Zgoda V. Proteomic Approach for Searching for Universal, Tissue-Specific, and LineSpecific Markers of Extracellular Vesicles in Lung and Colorectal Adenocarcinoma Cell Lines. Int J Mol Sci. 2020;21:18.

95. Kharaziha P, Ceder S, Li Q, Panaretakis T. Tumor cell-derived exosomes: a message in a bottle. Biochim Biophys Acta. 2012;1826(1):103-11.

96. Hoshino A, Costa-Silva B, Shen TL, Rodrigues G, Hashimoto A, Tesic Mark M, et al. Tumour exosome integrins determine organotropic metastasis. Nature. 2015;527(7578):329-35.

97. Peinado H, Zhang H, Matei IR, Costa-Silva B, Hoshino A, Rodrigues G, et al. Pre-metastatic niches: organ-specific homes for metastases. Nat Rev Cancer. 2017:17(5):302-17.

98. Kholia S, Ranghino A, Garnieri P, Lopatina T, Deregibus MC, Rispoli P, et al. Extracellular vesicles as new players in angiogenesis. Vasc Pharmacol. 2016; 86:64-70.

99. Whiteside TL. Tumor-Derived Exosomes and Their Role in Tumor-Induced Immune Suppression. Vaccines (Basel). 2016;4

100. Pyzer AR, Cole L, Rosenblatt J, Avigan DE. Myeloid-derived suppressor cells as effectors of immune suppression in cancer. Int J Cancer. 2016;139(9): 1915-26.

101. Wieckowski EU, Visus C, Szajnik M, Szczepanski MJ, Storkus WJ, Whiteside TL. Tumor-derived microvesicles promote regulatory $T$ cell expansion and induce apoptosis in tumor-reactive activated CD8+ T lymphocytes. J Immunol. 2009;183(6):3720-30

102. Bebawy M, Combes V, Lee E, Jaiswal R, Gong J, Bonhoure A, et al, Membrane microparticles mediate transfer of P-glycoprotein to drug sensitive cancer cells. Leukemia. 2009;23(9):1643-9.

103. Hong CS, Funk S, Whiteside TL. Isolation of Biologically Active Exosomes from Plasma of Patients with Cancer. Methods Mol Biol. 2017:1633:257-65.

104. Li X, Wang S, Zhu R, Li H, Han Q, Zhao RC. Lung tumor exosomes induce a pro-inflammatory phenotype in mesenchymal stem cells via NFkappaB-TLR signaling pathway. J Hematol Oncol. 2016;9:42.

105. Kim J, Hong SW, Kim S, Kim D, Hur DY, Jin DH, et al. Cyclooxygenase-2 expression is induced by celecoxib treatment in lung cancer cells and is transferred to neighbor cells via exosomes. Int J Oncol. 2018;52(2):613-20.

106. Clark DJ, Fondrie WE, Yang A, Mao L. Triple SILAC quantitative proteomic analysis reveals differential abundance of cell signaling proteins between normal and lung cancer-derived exosomes. J Proteome. 2016;133:161-9. 
107. Qi Y, Zha W, Zhang W. Exosomal miR-660-5p promotes tumor growth and metastasis in non-small cell lung cancer. J BUON. 2019;24(2):599-607.

108. Zhang N, Nan A, Chen L, Li X, Jia Y, Qiu M, et al. Circular RNA circSATB2 promotes progression of non-small cell lung cancer cells. Mol Cancer. 2020; 19(1):101.

109. Taverna S, Pucci M, Giallombardo M, Di Bella MA, Santarpia M, Reclusa P, et al. Amphiregulin contained in NSCLC-exosomes induces osteoclast differentiation through the activation of EGFR pathway. Sci Rep. 2017;7(1): 3170.

110. Liu Y, Luo F, Wang B, Li H, Xu Y, Liu X, et al. STAT3-regulated exosomal miR21 promotes angiogenesis and is involved in neoplastic processes of transformed human bronchial epithelial cells. Cancer Lett. 2016;370(1):12535.

111. Cui H, Seubert B, Stahl E, Dietz H, Reuning U, Moreno-Leon L, et al. Tissue inhibitor of metalloproteinases-1 induces a pro-tumourigenic increase of miR-210 in lung adenocarcinoma cells and their exosomes. Oncogene. 2015:34(28):3640-50

112. Valencia K, Luis-Ravelo D, Bovy N, Anton I, Martinez-Canarias S, Zandueta C, et al. miRNA cargo within exosome-like vesicle transfer influences metastatic bone colonization. Mol Oncol. 2014;8(3):689-703.

113. Liu Y, Gu Y, Cao X. The exosomes in tumor immunity. Oncoimmunology. 2015;4(9):e1027472.

114. Chalmin F, Ladoire S, Mignot G, Vincent J, Bruchard M, Remy-Martin JP, et al. Membrane-associated Hsp72 from tumor-derived exosomes mediates STAT3-dependent immunosuppressive function of mouse and human myeloid-derived suppressor cells. J Clin Invest. 2010;120(2):457-71.

115. Fabbri M, Paone A, Calore F, Galli R, Gaudio E, Santhanam R, et al. MicroRNAs bind to Toll-like receptors to induce prometastatic inflammatory response. Proc Natl Acad Sci U S A. 2012;109(31):E2110-6.

116. Rabinowits G, Gercel-Taylor C, Day JM, Taylor DD, Kloecker GH. Exosomal microRNA: a diagnostic marker for lung cancer. Clin Lung Cancer. 2009; 10(1):42-6.

117. Peng XX, Yu RY, Wu X, Wu SY, Pi C, Chen ZH, et al. Correlation of plasma exosomal microRNAs with the efficacy of immunotherapy in EGFR / ALK wild-type advanced non-small cell lung cancer. J Immunother Cancer. 2020; $8: 1$

118. Jin X, Chen Y, Chen H, Fei S, Chen D, Cai X, et al. Evaluation of TumorDerived Exosomal miRNA as Potential Diagnostic Biomarkers for Early-Stage Non-Small Cell Lung Cancer Using Next-Generation Sequencing. Clin Cancer Res. 2017:23(17):5311-9.

119. Wu Q, Yu L, Lin X, Zheng Q, Zhang S, Chen D, et al. Combination of Serum miRNAs with Serum Exosomal miRNAs in Early Diagnosis for Non-Small-Cell Lung Cancer. Cancer Manag Res. 2020;12:485-95.

120. Li C, LV Y, Shao C, Chen C, Zhang T, Wei Y, et al. Tumor-derived exosomal IncRNA GAS5 as a biomarker for early-stage non-small-cell lung cancer diagnosis. J Cell Physiol. 2019;234(11):20721-7.

121. Krug AK, Enderle D, Karlovich C, Priewasser T, Bentink S, Spiel A, et al. Improved EGFR mutation detection using combined exosomal RNA and circulating tumor DNA in NSCLC patient plasma. Ann Oncol. 2018;29(3):7006.

122. Thakur BK, Zhang H, Becker A, Matei I, Huang Y, Costa-Silva B, et al. Doublestranded DNA in exosomes: a novel biomarker in cancer detection. Cell Res. 2014;24(6):766-9.

123. Li Y, Zhang Y, Qiu F, Qiu Z. Proteomic identification of exosomal LRG1: a potential urinary biomarker for detecting NSCLC. Electrophoresis. 2011; 32(15):1976-83.

124. Yamashita $T$, Kamada $H$, Kanasaki $S$, Maeda $Y$, Nagano $K$, Abe $Y$, et al. Epidermal growth factor receptor localized to exosome membranes as a possible biomarker for lung cancer diagnosis. Pharmazie. 2013;68(12):96973.

125. Sandfeld-Paulsen B, Jakobsen KR, Baek R, Folkersen BH, Rasmussen TR, Meldgaard $\mathrm{P}$, et al. Exosomal Proteins as Diagnostic Biomarkers in Lung Cancer. J Thorac Oncol. 2016;11(10):1701-10.

126. Gao J, Qiu X, Li X, Fan H, Zhang F, Lv T, et al. Expression profiles and clinical value of plasma exosomal Tim-3 and Galectin-9 in non-small cell lung cancer. Biochem Biophys Res Commun. 2018:498(3):409-15.

127. Song Z, Cai Z, Yan J, Shao YW, Zhang Y. Liquid biopsies using pleural effusion-derived exosomal DNA in advanced lung adenocarcinoma. Transl Lung Cancer Res. 2019;8(4):392-400
128. Fan TWM, Zhang X, Wang C, Yang Y, Kang WY, Arnold S, et al. Exosomal lipids for classifying early and late stage non-small cell lung cancer. Anal Chim Acta. 2018;1037:256-64.

129. Sandfeld-Paulsen B, Aggerholm-Pedersen N, Baek R, Jakobsen KR, Meldgaard P, Folkersen $\mathrm{BH}$, et al. Exosomal proteins as prognostic biomarkers in non-small cell lung cancer. Mol Oncol. 2016;10(10):1595-602.

130. Liu Q, Yu Z, Yuan S, Xie W, Li C, Hu Z, et al. Circulating exosomal microRNAs as prognostic biomarkers for non-small-cell lung cancer. Oncotarget. 2017; 8(8):13048-58

131. Yuwen DL, Sheng BB, Liu J, Wenyu W, Shu YQ. MiR-146a-5p level in serum exosomes predicts therapeutic effect of cisplatin in non-small cell lung cancer. Eur Rev Med Pharmacol Sci. 2017;21(11):2650-8.

132. Munagala R, Aqil F, Gupta RC. Exosomal miRNAs as biomarkers of recurrent lung cancer. Tumour Biol. 2016;37(8):10703-14.

133. Dejima $H$, linuma $H$, Kanaoka $R$, Matsutani N, Kawamura M. Exosomal microRNA in plasma as a non-invasive biomarker for the recurrence of nonsmall cell lung cancer. Oncol Lett. 2017;13(3):1256-63.

134. Kobayashi S, Boggon TJ, Dayaram T, Janne PA, Kocher O, Meyerson M, et al. EGFR mutation and resistance of non-small-cell lung cancer to gefitinib. N Engl J Med. 2005;352(8):786-92.

135. Xiao X, Yu S, Li S, Wu J, Ma R, Cao H, et al. Exosomes: decreased sensitivity of lung cancer A549 cells to cisplatin. PLoS One. 2014;9(2):e89534.

136. Lobb RJ, van Amerongen R, Wiegmans A, Ham S, Larsen JE, Moller A. Exosomes derived from mesenchymal non-small cell lung cancer cells promote chemoresistance. Int J Cancer. 2017;141(3):614-20.

137. Yuan D, Xu J, Wang J, Pan Y, Fu J, Bai Y, et al. Extracellular miR-1246 promotes lung cancer cell proliferation and enhances radioresistance by directly targeting DR5. Oncotarget. 2016;7(22):32707-22.

138. Tang Y, Cui Y, Li Z, Jiao Z, Zhang Y, He Y, et al. Radiation-induced miR-208a increases the proliferation and radioresistance by targeting p21 in human lung cancer cells. J Exp Clin Cancer Res. 2016;35:7.

139. Munagala R, Aqil F, Jeyabalan J, Agrawal AK, Mudd AM, Kyakulaga AH, et al. Exosomal formulation of anthocyanidins against multiple cancer types. Cancer Lett. 2017;393:94-102.

140. Kim MS, Haney MJ, Zhao Y, Mahajan V, Deygen I, Klyachko NL, et al. Development of exosome-encapsulated paclitaxel to overcome MDR in cancer cells. Nanomedicine. 2016;12(3):655-64.

141. Agrawal AK, Aqil F, Jeyabalan J, Spencer WA, Beck J, Gachuki BW, et al. Milkderived exosomes for oral delivery of paclitaxel. Nanomedicine. 2017;13(5): $1627-36$.

142. Hoshino D, Kirkbride KC, Costello K, Clark ES, Sinha S, Grega-Larson N, et al. Exosome secretion is enhanced by invadopodia and drives invasive behavior. Cell Rep. 2013;5(5):1159-68.

143. Eldridge L, Moldobaeva A, Zhong Q, Jenkins J, Snyder M, Brown RH, et al. Bronchial Artery Angiogenesis Drives Lung Tumor Growth. Cancer Res. 2016;76(20):5962-9.

144. Ridder K, Sevko A, Heide J, Dams M, Rupp AK, Macas J, et al. Extracellular vesicle-mediated transfer of functional RNA in the tumor microenvironment Oncoimmunology. 2015;4(6):e1008371.

145. Bard MP, Hegmans JP, Hemmes A, Luider TM, Willemsen R, Severijnen LA, et al. Proteomic analysis of exosomes isolated from human malignant pleural effusions. Am J Respir Cell Mol Biol. 2004;31(1):114-21.

146. Jakobsen KR, Paulsen BS, Baek R, Varming K, Sorensen BS, Jorgensen MM. Exosomal proteins as potential diagnostic markers in advanced non-small cell lung carcinoma. J Extracell Vesicles. 2015:4:26659.

147. Solomon BJ, Mok T, Kim DW, Wu YL, Nakagawa K, Mekhail T, et al. First-line crizotinib versus chemotherapy in ALK-positive lung cancer. N Engl J Med. 2014;371(23):2167-77.

148. Li N, Huang Z, Zhang X, Song X, Xiao Y. Reflecting Size Differences of Exosomes by Using the Combination of Membrane-Targeting Viscosity Probe and Fluorescence Lifetime Imaging Microscopy. Anal Chem. 2019; 91(23):15308-16.

149. Yang JS, Lee JC, Byeon SK, Rha KH, Moon MH. Size Dependent Lipidomic Analysis of Urinary Exosomes from Patients with Prostate Cancer by Flow Field-Flow Fractionation and Nanoflow Liquid Chromatography-Tandem Mass Spectrometry. Anal Chem. 2017;89(4):2488-96.

150. Gordon-Alonso M, Yanez-Mo M, Barreiro O, Alvarez S, Munoz-Fernandez MA Valenzuela-Fernandez A, et al. Tetraspanins CD9 and CD81 modulate HIV-1induced membrane fusion. J Immunol. 2006;177(8):5129-37. 
151. Kamerkar S, LeBleu VS, Sugimoto H, Yang S, Ruivo CF, Melo SA, et al. Exosomes facilitate therapeutic targeting of oncogenic KRAS in pancreatic cancer. Nature. 2017:546(7659):498-503.

152. Majeti R, Chao MP, Alizadeh AA, Pang WW, Jaiswal S, Gibbs KD Jr, et al. CD47 is an adverse prognostic factor and therapeutic antibody target on human acute myeloid leukemia stem cells. Cell. 2009;138(2):286-99.

153. Luan X, Sansanaphongpricha K, Myers I, Chen H, Yuan H, Sun D. Engineering exosomes as refined biological nanoplatforms for drug delivery. Acta Pharmacol Sin. 2017;38(6):754-63.

154. Srivastava A, Babu A, Filant J, Moxley KM, Ruskin R, Dhanasekaran D, et al. Exploitation of Exosomes as Nanocarriers for Gene-, Chemo-, and ImmuneTherapy of Cancer. J Biomed Nanotechnol. 2016;12(6):1159-73.

155. Wood SL, Pernemalm M, Crosbie PA, Whetton AD. The role of the tumormicroenvironment in lung cancer-metastasis and its relationship to potential therapeutic targets. Cancer Treat Rev. 2014:40(4):558-66.

156. Kaplan RN, Riba RD, Zacharoulis S, Bramley AH, Vincent L, Costa C, et al. VEGFR1-positive haematopoietic bone marrow progenitors initiate the premetastatic niche. Nature. 2005;438(7069):820-7.

157. Arandkar S, Furth N, Elisha Y, Nataraj NB, van der Kuip H, Yarden Y, et al. Altered p53 functionality in cancer-associated fibroblasts contributes to their cancer-supporting features. Proc Natl Acad Sci U S A. 2018;115(25):6410-5.

158. Novo D, Heath N, Mitchell L, Caligiuri G, MacFarlane A, Reijmer D, et al. Mutant p53s generate pro-invasive niches by influencing exosome podocalyxin levels. Nat Commun. 2018;9(1):5069.

159. Wang $Y, Y i J$, Chen $X$, Zhang $Y, X u$ M, Yang $Z$. The regulation of cancer cell migration by lung cancer cell-derived exosomes through TGF-beta and IL10. Oncol Lett. 2016;11(2):1527-30.

160. Kim J, Kim TY, Lee MS, Mun JY, Ihm C, Kim SA. Exosome cargo reflects TGFbeta1-mediated epithelial-to-mesenchymal transition (EMT) status in A549 human lung adenocarcinoma cells. Biochem Biophys Res Commun. 2016; 478(2):643-8.

161. Hsu YL, Hung JY, Chang WA, Lin YS, Pan YC, Tsai PH, et al. Hypoxic lung cancer-secreted exosomal miR-23a increased angiogenesis and vascular permeability by targeting prolyl hydroxylase and tight junction protein ZO1. Oncogene. 2017:36(34):4929-42.

162. Huang SH, Li Y, Zhang J, Rong J, Ye S. Epidermal growth factor receptorcontaining exosomes induce tumor-specific regulatory $T$ cells. Cancer Investig. 2013;31(5):330-5.

163. Cazzoli R, Buttitta F, Di Nicola M, Malatesta S, Marchetti A, Rom WN, et al. microRNAs derived from circulating exosomes as noninvasive biomarkers for screening and diagnosing lung cancer. J Thorac Oncol. 2013;8(9):115662.

164. Zhang Y, Zhang Y, Yin Y, Li S. Detection of circulating exosomal miR-17-5p serves as a novel non-invasive diagnostic marker for non-small cell lung cancer patients. Pathol Res Pract. 2019;215(8):152466.

165. Dinh TK, Fendler W, Chalubinska-Fendler J, Acharya SS, O'Leary C, Deraska $\mathrm{PV}$, et al. Circulating miR-29a and miR-150 correlate with delivered dose during thoracic radiation therapy for non-small cell lung cancer. Radiat Oncol. 2016:11:61.

166. Vogelstein B, Papadopoulos N, Velculescu VE, Zhou S, Diaz LA Jr, Kinzler KW. Cancer genome landscapes. Science. 2013;339(6127):1546-58.

167. Arbour KC, Riely GJ. Systemic Therapy for Locally Advanced and Metastatic Non-Small Cell Lung Cancer: A Review. JAMA. 2019;322(8):764-74.

168. Tun AM, Thein KZ, Thein WL, Guevara E. Checkpoint inhibitors plus chemotherapy for first-line treatment of advanced non-small cell lung cancer: a systematic review and meta-analysis of randomized controlled trials. Future Sci OA. 2019:5(9):FSO421.

169. Lynch TJ, Bell DW, Sordella R, Gurubhagavatula S, Okimoto RA, Brannigan BW, et al. Activating mutations in the epidermal growth factor receptor underlying responsiveness of non-small-cell lung cancer to gefitinib. $\mathrm{N}$ Engl J Med. 2004;350(21):2129-39.

170. Mashouri L, Yousefi H, Aref AR, Ahadi AM, Molaei F, Alahari SK. Exosomes: composition, biogenesis, and mechanisms in cancer metastasis and drug resistance. Mol Cancer. 2019:18(1):75.

171. Li XQ, Liu JT, Fan LL, Liu Y, Cheng L, Wang F, et al. Exosomes derived from gefitinib-treated EGFR-mutant lung cancer cells alter cisplatin sensitivity via up-regulating autophagy. Oncotarget. 2016;7(17):24585-95.

172. Qin X, Yu S, Zhou L, Shi M, Hu Y, Xu X, et al. Cisplatin-resistant lung cancer cell-derived exosomes increase cisplatin resistance of recipient cells in exosomal miR-100-5p-dependent manner. Int J Nanomedicine. 2017;12: 3721-33.
173. Jing C, Cao H, Qin X, Yu S, Wu J, Wang Z, et al. Exosome-mediated gefitinib resistance in lung cancer HCC827 cells via delivery of miR-21. Oncol Lett. 2018;15(6):9811-7.

174. Riazifar M, Mohammadi MR, Pone EJ, Yeri A, Lasser C, Segaliny Al, et al. Stem Cell-Derived Exosomes as Nanotherapeutics for Autoimmune and Neurodegenerative Disorders. ACS Nano. 2019;13(6):6670-88.

175. Clayton A, Harris CL, Court J, Mason MD, Morgan BP. Antigen-presenting cell exosomes are protected from complement-mediated lysis by expression of CD55 and CD59. Eur J Immunol. 2003;33(2):522-31.

176. Aqil F, Kausar H, Agrawal AK, Jeyabalan J, Kyakulaga AH, Munagala R, et al. Exosomal formulation enhances therapeutic response of celastrol against lung cancer. Exp Mol Pathol. 2016;101(1):12-21.

177. Srivastava A, Amreddy N, Babu A, Panneerselvam J, Mehta M, Muralidharan $R$, et al. Nanosomes carrying doxorubicin exhibit potent anticancer activity against human lung cancer cells. Sci Rep. 2016;6:38541.

178. El Andaloussi S, Lakhal S, Mager I, Wood MJ. Exosomes for targeted siRNA delivery across biological barriers. Adv Drug Deliv Rev. 2013;65(3):391-7.

179. Qi H, Liu C, Long L, Ren Y, Zhang S, Chang X, et al. Blood Exosomes Endowed with Magnetic and Targeting Properties for Cancer Therapy. ACS Nano. 2016;10(3):3323-33.

180. Sadana A, Vo-Dinh T. Antibody-antigen binding kinetics. A model for multivalency antibodies for large antigen systems. Appl Biochem Biotechnol. 1997;67(1-2):1-22.

181. Zhang P, Wang C, Zhao J, Xiao A, Shen Q, Li L, et al. Near Infrared-Guided Smart Nanocarriers for MicroRNA-Controlled Release of Doxorubicin/siRNA with Intracellular ATP as Fuel. ACS Nano. 2016;10(3):3637-47.

182. Wang J, Dong Y, Li Y, Li W, Cheng K, Qian Y, et al. Designer Exosomes for Active Targeted Chemo-Photothermal Synergistic Tumor Therapy. Adv Functional Mat. 2018;28:18.

183. Acharya S, Sahoo SK. PLGA nanoparticles containing various anticancer agents and tumour delivery by EPR effect. Adv Drug Deliv Rev. 2011;63(3): 170-83.

184. Meng Z, Zhou X, Xu J, Han X, Dong Z, Wang H, et al. Light-Triggered In Situ Gelation to Enable Robust Photodynamic-Immunotherapy by Repeated Stimulations. Adv Mater. 2019:31(24):e1900927.

185. Liu C, Zhang W, Li Y, Chang J, Tian F, Zhao F, et al. Microfluidic Sonication To Assemble Exosome Membrane-Coated Nanoparticles for Immune Evasion-Mediated Targeting. Nano Lett. 2019;19(11):7836-44.

186. Li S, Wu Y, Ding F, Yang J, Li J, Gao X, et al. Engineering macrophagederived exosomes for targeted chemotherapy of triple-negative breast cancer. Nanoscale. 2020.

187. Walker S, Busatto S, Pham A, Tian M, Suh A, Carson K, et al. Extracellular vesicle-based drug delivery systems for cancer treatment. Theranostics. 2019:9(26):8001-17.

\section{Publisher's Note}

Springer Nature remains neutral with regard to jurisdictional claims in published maps and institutional affiliations.
Ready to submit your research? Choose BMC and benefit from:

- fast, convenient online submission

- thorough peer review by experienced researchers in your field

- rapid publication on acceptance

- support for research data, including large and complex data types

- gold Open Access which fosters wider collaboration and increased citations

- maximum visibility for your research: over $100 \mathrm{M}$ website views per year

At $\mathrm{BMC}$, research is always in progress.

Learn more biomedcentral.com/submissions 